\title{
SPECIFICITY AND PLASTICITY OF RETINOTECTAL CONNECTIONS: A COMPUTATIONAL MODEL ${ }^{1}$
}

\author{
V. A. WHITELAW AND J. D. COWAN ${ }^{2}$ \\ Department of Biophysics and Theoretical Biology and Committee on Neurobiology, The University of Chicago, Chicago, Illinois 60637
}

\begin{abstract}
A computational model is presented which simulates the development and regeneration of orderly connections between retinal fibers and tectal cells in frogs and goldfish. The model distinguishes two aspects of retinotectal connectivity: (1) the contact adhesion between retinal fibers and tectal cells as mediated by fixed chemospecific markers and (2) the formation of modifiable synapses between them. Chemospecificity is assumed to be an intrinsic property of both the retina and tectum and is modeled as a graded distribution of a binding determinant or marker. Synapse formation depends upon the timing of neural activity as well as on the intinsic chemospecificity of retinotectal contacts. In addition to the normal development and regeneration of the retinotectal map, the model simulates the compressed, expanded, translocated, and rotated maps that have been found in surgically manipulated contexts. These examples of plasticity in the retinotectal map can be simulated without assuming any changes in the marker distributions. Moreover, the model demonstrates that a very shallow gradient of a single marker suffices to organize retinotectal connections in a variety of contexts.
\end{abstract}

The intricacy of the brain is nowhere more evident than in its elaborate but precise patterns of interconnection. A striking example of this is to be found in the vertebrate visual pathway in which the neural representation of visual space is preserved through a series of maps from the retina to progressively more central regions of the brain (Polyak, 1975). The neural connections which generate such maps have been investigated in considerable detail, particularly in the lower vertebrates whose main visual centers are the optic tecta. This paper presents a computational model of how the orderly pattern of connections from retina to tectum is established during development and re-established during regeneration.

The model treats separately two aspects of retinotectal

\footnotetext{
${ }^{1}$ The work reported in this paper was supported in part by a United States Senior Scientist Award to one of us (J. D. C.) by the Alexander von Humboldt Foundation, sponsored by Professor O. D. Creutzfeldt and M. Eigen of the Max-Planck-Institut fur Biophysikalische Chemie, Gottingen, West Germany; in part by the Department of Mathematics, University of British Columbia, sponsored by Professor R. M. Miura when one of us (J. D. C.) was a guest there; and by United States Public Health Service Grants TG GM 2037 (J. D. C.) and GM 07183 (V. A. W.). We are most appreciative of this support. We acknowledge the great help provided by D. J. Willshaw and especially by C. von der Malsburg in the formulation of a precursor of the model described in this paper. Finally, we thank C. von der Malsburg, M. Hollyday, and P. Grobstein for their careful reading of the manuscript.

${ }^{2}$ To whom correspondence should be addressed.
}

connectivity: (1) the adhesion of retinal and tectal cells as mediated by putative chemical markers and (2) the formation of modifiable synapses between retinal fibers and tectal cells. Sperry (1941) first proposed that orderly neuronal connections form under the influence of selective biochemical affinities between cells. This idea is now known as the chemospecificity hypothesis. Hebb (1949) first proposed that synaptic efficacy or strength can change with neural activity. This proposal has since been refined and given physiological interpretations, most recently by Stent (1973). These two postulates have been given mathematical expressions in the present model describing the behavior of retinotectal connections over time. Application of these equations to both normal and surgically contrived situations successfully simulates many experimental contexts.

Early support for the chemospecificity hypothesis in the context of retinotectal connections was inferred from observations of regenerating maps in goldfish. Attardi and Sperry (1963) made partial retinal ablations, cut the optic nerve, and studied the subsequent regenerated projections to intact tecta. They repeatedly found that only tectal regions normally connected to the spared retinal half became reinnervated. Studies of the patterns of regeneration following eye rotations and nerve section also were performed and the findings were consistent: optic axons grew back to their normal tectal targets despite the aberrant positions of those target cells.

Sperry (1944) articulated the application of the che- 
mospecificity hypothesis to retinotectal connections as follows:

This orderly restoration of central reflex relations occurs regardless of the orientation of the retina ... and must therefore be regulated by growth factors independently of functional adaptation. As this would otherwise be impossible, the growing optic fibers must possess specific properties of some sort by which they are differentially distinguished...

The orderly topographical arrangement of functional relations found in the optic lobe after optic nerve regeneration is difficult to explain without assuming that the secondary neurons of the optic tectum are also biochemically dissimilaı.

The present model incorporates "biochemical dissimilarity" as a graded distribution of a marker irreversibly fixed in the retina and tectum prior to the development of the retinotectal map. The experimental basis for these assumptions will be reviewed briefly.

There is no direct molecular evidence of biochemical labels which are involved in retinotectal connectivity. The existence of such labels has been inferred from adhesion studies (done mostly in chick) which demonstrate an adhesive preference on the part of retinal fragments for the tectal fragments to which they normally connect (Barbera et al., 1973; Barbera, 1975; Balsamo et al., 1976). Recent studies using monoclonal antibodies have uncovered a gradient of a membrane-bound molecule in the chick retina (D. Trisler, personal communication); the involvement of this gradient in retinotectal connectivity remains unclear.

Indirect evidence for the existence of markers has come from surgical manipulations of the retinotectal systern. Retinal markers have been inferred from such studies as eye rotations in which appropriately rotated retinotectal maps result (Hunt and Jacobson, 1972a, b; Gaze et al., 1979). Similarly, the existence of tectal labels has been inferred from tectal rotations done prior to optic innervation (Chung and Cooke, 1975; Straznicky, 1978). Again, rotated maps result. Tectal graft translocation and rotation studies (Sharma and Gaze, 1971; Yoon, 1973; Levine and Jacobson, 1974; Jacobson and Levine, $1975 \mathrm{a}, \mathrm{b})$ also provide evidence for retinal and tectal markers. When such manipulations are done on frogs or goldfish subsequent to the development of a normal retinotectal map, the retinal fibers usually regenerate to their original tectal targets despite the fact that those targets have been moved to new positions. This results in discontinuities in the retinotectal map.

A critical recognition between retinal fibers and tectal cells is implied by these findings. Both the retinal and tectal cells must in some way be individuated for this selectivity to occur. Because these manipulations have been performed only after normal development, they do not address the question of whether the tectal labels are intrinsic or retinally induced. A previous model (Willshaw and von der Malsburg, 1979) exploited the latter possibility. The present model, on the basis of the early tectal rotation studies as well as other evidence which will be discussed later, assumes that tectal labels are intrinsic.

As stated above, tectal graft manipulations usually result in discontinuous retinotental maps as retinal fibers return to their original tectal targets. Sometimes, however, a continuous retinotectal map results, implying that retinal fibers can connect with abnormal tectal targets. While this occurs relatively infrequently, the fact that it occurs at all implies that chemical specificity is not the sole influence in map formation. These dual results which have been described consistently in the tectal graft manipulation studies present a challenge to any retinotectal model for explanation and reconciliation.

Tectal graft manipulations have provided evidence for both specificity-conferring retinal and tectal markers as well as plasticity in retinotectal connectivity. Other experiments also have demonstrated plasticity in connections. For example, the partial retinal ablation studies done by Attardi and Sperry (1963) have since been redone and followed over longer time courses (Horder, 1971; Yoon, 1972a, b). The initial confinement of the hemi-retinal projection to the appropriate half-tectum has been confirmed for the short time course studied by Attardi and Sperry. However, over longer time courses, expanded maps are found; that is, the hemi-retinal projection is restricted early on but eventually expands over the entire tectal surface. Consequently, many retinal fibers must connect with abnormal tectal targets. Similar results are obtained in the case of partial tectal ablations (Gaze and Sharma, 1970; Yoon, 1976). At first, only the appropriate retinal half re-establishes connections with what remains of the tectum, but eventually, an orderly compressed map of the entire retina is established.

These results are considered examples of plasticity in the retinotectal system because they involve connections between regions of retina and tectum which do not normally connect. Evidence for neural plasticity often has been interpreted as evidence against chemospecificity. It is a challenge to any model of the retinotectal system to articulate compatible mechanisms for both the specificity and plasticity of connections as they occur in experimental contexts.

One mechanism that has been proposed for reconciling the specificity and plasticity of connections is marker regulation. The specificity is assumed to result from marker distributions, but the marker distributions are assumed to change following surgical cuts. "Regulation" is a term borrowed from embryology and refers to the redistribution of putative differentiating factors following surgical ablation. Here it applies to a surgically induced redistribution of the putative chemical markers involved in retinotectal connectivity.

Experiments designed to test whether marker regulation occurs in the retinotectal system in fact provide evidence that it does not (Meyer, 1975, 1978; Hunt, 1977; Cook and Horder, 1977; Schmidt, 1978). For example, in an experiment done by Schmidt (1978), the expanded projection from a half-retina was interrupted. The hemiretinal fibers were deflected onto the normally innervated ipsilateral tectum. If the cut retina had undergone regulation, it would have formed an expanded projection on the control tectum. It did not. Instead, only the appropriate half of the tectum received input from the halfretina.

Evidence against tectal marker regulation comes from graft translocation studies. These experiments have been done only following initial development of a retinotectal 
map; however, they have been done following the initial development of a surgically scrambled projection (Fraser and Hunt, 1980). If tectal markers were changed or aberrantly induced by the initially scrambled projection, regeneration would have been similarly confused. It was not. Instead, retinal regions grew back to the tectal regions to which they would normally connect.

In line with the evidence against regulation, the assumption made in the present model is that the retinal and tectal marker distributions are fixed. Plasticity in connections is shown to result from changes in context, not from changes in marker distributions. These markers are assumed to mediate differential adhesiveness between retinal and tectal cells. The adhesiveness of any retinotectal cell pair is calculated as a function of their respective marker concentrations and is correlated with the energy required to separate them. The inter-adhesion of retinal and tectal cells is distinguished from the formation of synapses between them. The adhesion coefficient for each retinotectal cell pair is a fixed quantity. The formation of a synapse between them is a modifiable process.

The efficacy of symaptic transmission will be referred to as "synaptic strength." In the present model, synaptic strength is assumed to be modifiable by neural activity. The general idea that synapses can be modified by activity has considerable precedence in experimental findings and theoretical treatments of the nervous system (for example, see Hebb, 1949; Brindley, 1967; Stent, 1973; Willshaw and von der Malsburg, 1976; Changeux and Danchin, 1976). The particular assumptions made here about the interplay between synaptic strength and neural activity are patterned after Hebb (1949). He proposed that synchronous pre- and postsynaptic activity strengthened synapses, whereas asynchronous activity weakened them.

Stent (1973) proposed a physiological basis for this selective growth of synapses. He suggested that the stability of receptor protein for binding neurotransmitter depends upon an inward gradient of electrical potential: the more hyperpolarized the membrane, the more stable the receptor protein. He reasoned that, during depolarization, the receptor can still be stabilized only if it binds neurotransmitter. Therefore, if a cell is depolarized under the influence of one of several inputs, the receptor proteins at its inactive synapses are destabilized, which, after repeated occurrence, will destroy the efficacy of those synapses.

The model assumes that the strength of the retinotectal synapse is increased only if depolarization of the tectal cell can be correlated consistently with the firing of the retinal cell. The strength of the synapse decreases if the tectal cell repeatedly depolarizes due to other influences (i.e., intratectal connections). The assumptions made about neural activity are 2-fold: (1) a cluster of neighboring retinal cells (two to five) fire synchronously, depolarizing the tectal cells to which they connect and (2) the recipient tectal cells further depolarize their nearest tectal neighbors. Under these conditions, some synapses will be strengthened; others will be weakened.

These assumptions are consistent with what is known of the synaptic machinery and events in the retinotectal system. For example, spontaneous activity is known to occur in retinal ganglion cells (Rodieck, 1973). In some species, there is a dramatic increase in ganglion cell activity during the early stages in the formation of the retinotectal map (R. M. Gaze, personal communication), and there is good evidence that the activity of neighboring ganglion cells is synchronous (Mastronarde, 1979). Ganglion cells receive input from retinal interneurons whose interconnections could mediate neighbor correlations in ganglion cell activity. Tectal cells, in addition to receiving ganglion cell input, share dendrodendritic synapses with other tectal cells (Szekely et al., 1973). Such synapses could mediate neighbor correlations in tectal cell activity.

The model combines fixed chemospecificities with the modification of synaptic strengths in the following way: the chemospecific adhesion of each retinotectal cell pair determines the rate of growth or decay of the synaptic strength between them. Hence, chemospecificity is a weighting function for the modification of synaptic strengths.

With its novel combination of fixed chemospecificities and modifiable synaptic strengths, this model can account for much of the specificity and plasticity found experimentally in the retinotectal system. In particular, the model successfully predicts the normal development and regeneration of the retinotectal map; it correctly simulates the retinae and tecta rotation studies as well as the size mismatch experiments involving partial retinal or tectal ablations. Finally, the model addresses the apparently contradictory findings of tectal graft manipulations and offers an explanation for the dual results.

\section{The Model}

The general requirements of the model are as follows: (1) it must contain a mechanism by which retinotectal contacts can be made and synapses can form. (2) If it is to be at all plastic, it must incorporate a means by which synapses can decay and contacts can break. (3) It must generate a local ordering of connections; that is, it must preserve retinotopy. (4) It must provide some polarity information to produce properly oriented retinotectal maps.

In the model described here, synaptic growth is induced by retinal activity. The rate of synaptic growth for each retinotectal cell pair is weighted by the chemospecific adhesion between them. Synaptic decay is induced by nearest neighbor tectal depolarization that is not synchronous with retinal activity. Local ordering is achieved through competition among retinal fibers for tectal contacts and among tectal cells for retinal input. Global polarity information is supplied by the gradients of marker concentrations assumed to exist in both the retina and tectum.

The mathematical articulation of these assumptions will be discussed in turn.

Retinal ganglion cell activity. The present model assumes that the timing of neural activity is central to the process of synapse formation; that is, it is through such activity that retinal fibers communicate their presence to the tectum. It is also assumed that nearest neighbor retinal activity is correlated; that is, the $i$ th retinal cell and its nearest neighbors, the $(i-1)$ th and $(i+1)$ th cells, are activated synchronously. The model calculates 
changes of activity on the time scale of individual synaptic events. Time is represented in discrete intervals during which the spontaneous activation of a retinal cell is considered to be coincident with the induced activation of its nearest neighbors. In effect, neighborhood relationships are defined in terms of temporal coincidence.

For each iteration of the calculations, a retinal cell $i$ is selected randomly to become active and, thus, to induce activity in its nearest neighbors. The electrical states of these fibers, $r_{i}, r_{i-1}$, and $r_{i+1}$ are set equal to 1 ; the state of all other retinal fibers is set equal to 0 .

Tectal cell activity. Tectal cells are thought to receive at least two kinds of depolarizing input. One is through synapses that they share with retinal ganglion cells; the other is through synapses that they share with each other. As with retinal cell activity, the model assumes that, once tectal cells become active (by means of retinal input), they depolarize their nearest neighbors. Thus, just as in the retina, tectal neighborhood relationships are defined in terms of temporal coincidence.

The equation describing tectal cell activity has three terms. The first term is the superposition of active retinal inputs, weighted by the strength of the synapse currently shared. The next two terms describe the nearest neighbor spread of activity (in one dimension). The weighting factor, $b_{j^{\prime}, j}$, is a measure of the strength of intratectal synapses. It is assumed to be constant. The total depolarization of the $j$ th tectal cell then is given by:

$$
t_{j}=k \sum_{i=1}^{N_{r}} s_{i j} r_{i}+b_{j-1, j} t_{j-1}+b_{j+1, j} t_{j+1}
$$

where $k$ is a proportionality constant (see "Mathematical Appendix" for the definitions of the terms). The important point from equation 1 is that each tectal cell can be depolarized from retinal inputs as well as from tectal neighbors. As will be discussed in the next section, under this latter condition, synapses between retinal and tectal cells can be weakened selectively.

The modifiable synapse. The model assumes that synaptic modification is dependent upon the timing of neural activity. The change of synaptic strengths over time is described by a differential equation in which there are growth and decay terms. The motivation for the equation comes from an interpretation of Hebb's (1949) modifiable synapse, which was discussed in the introduction.

What is central to the model is not the particular physiology of the synapse but that it gets stronger if both pre- and postsynaptic cells are co-active and weaker if they are not. If one considers a particular synapse, $s_{i j}$, between retinal cell $i$ and tectal cell $j$, it is only strengthened if $j$ is depolarized by $i$. If $j$ is depolarized by some other retinal input or by a neighboring tectal cell, $s_{i j}$ is weakened. The differential equation governing the growth and decay of retinotectal synapses in the model is given by:

$$
\frac{d s_{i j}}{d t}=c_{i j} r_{i} t_{j}-\alpha t_{j}+\Omega
$$

where $c_{i j}$ is the chemospecific adhesion of the $i$-jth contact, $r_{i}$ and $t_{j}$ are the electrical states of the $i$ th retinal cell and $j$ th tectal cell, respectively, $\alpha$ is the rate constant for receptor protein destabilization (i.e., the rate at which the synapse decays due to asynchronous activity), and $\Omega$ is the flux term" (see "Mathematical Appendix" for a discussion of units).

All of the constants and variables in equation 2 are non-negative. The first term, $c_{i j} r_{i} t_{j}$, represents synaptic growth induced by synchronous retinotectal activity weighted by the adhesion $c_{i j}$ of the contact. For this term to be positive, both $r_{i}$ and $t_{j}$ must be non-zero. The decay term $-\alpha t_{j}$ comes into play if there is asynchronous activity, i.e., if $r_{i}=0$ and $t_{j}>0$. The flux term, $\Omega$, reflects the (random) chance that any connection can sprout. It is included in the equation to test the stability of the resulting retinotectal map to random sprouting. The synaptic conductance or strength, $s_{i j}$, is calculated for all $i-j$ contacts at each iteration. Many $s_{i j}$ values will be at or near 0 ; others will be relatively large. After a number of iterations, the overall pattern of synaptic strengths stabilizes as $d s_{i j} / d t$ tends to 0 . The end result is a stable matrix of synaptic strengths that can be compared with an experimentally generated retinotectal map.

Chemospecificity. The chemospecificity hypothesis is embodied in the adhesiveness coefficients, $c_{i j}$. Adhesive contacts are assumed to arise from the binding of membrane-bound markers, possibly glycolipids or glycoproteins, on the surfaces of retinal and tectal cells (Marchase et al., 1975; Glaser et al., 1977; Lilien et al., 1978). Graded concentrations of these markers provide retinal and tectal cells with positional as well as polarity information (Wolpert, 1969). "Polarity" in this context means the direction in which positional information is specified; it is encoded by the slope of the marker distributions.

Only one pair of axes is treated here, namely the nasotemporal axis of the retina and the corresponding caudorostral axis of the tectum. Only one marker, differentially distributed, is needed to specify one dimension. A graded distribution of this marker is assumed to be established irreversibly in both the retina and tectum prior to the innervation of the tectum by retinal fibers (see Fig. 1).

The concentration of the marker associated with the $i$ th retinal cell, $a_{i}$, or $j$ th tectal cell, $a_{j}$, is given by:

$$
a_{i}=2^{-\left(2 i / N_{r}\right)^{k}}+b ; a_{j}=2^{-\left(2 j / N_{t}\right)^{k}}+b
$$

where $N_{r}$ and $N_{t}$ are the numbers of cells in the pre- and postsynaptic arrays, respectively, $b$ is the base line level of the marker, and $\epsilon$ regulates the steepness of the marker gradient. The choice of values for $\epsilon$ and $b$ is not critical to the model. Any monotonic distribution from a shallow linear gradient to a steep sigmoid was found to be suitable. This in itself is a significant feature of the model to which we will return later. In the simulations which follow, $\epsilon=2, b=1$ has been used, which is the gradient diagrammed in Figure 1.

\footnotetext{
${ }^{3}$ In general terms, equation 2 may be thought of as computing the function $p(i / j)$, the probability of presynaptic event $j$, given the postsynaptic event $j$. Such a function will increase given the repeated occurrence of the event $(j, j)$, i.e., if the tectal cell depolarized repeatedly in the presence of activity in the ith fiber. Thus equation 2 is closely related to the "conditional probability synapse" of Uttley (1956).
} 


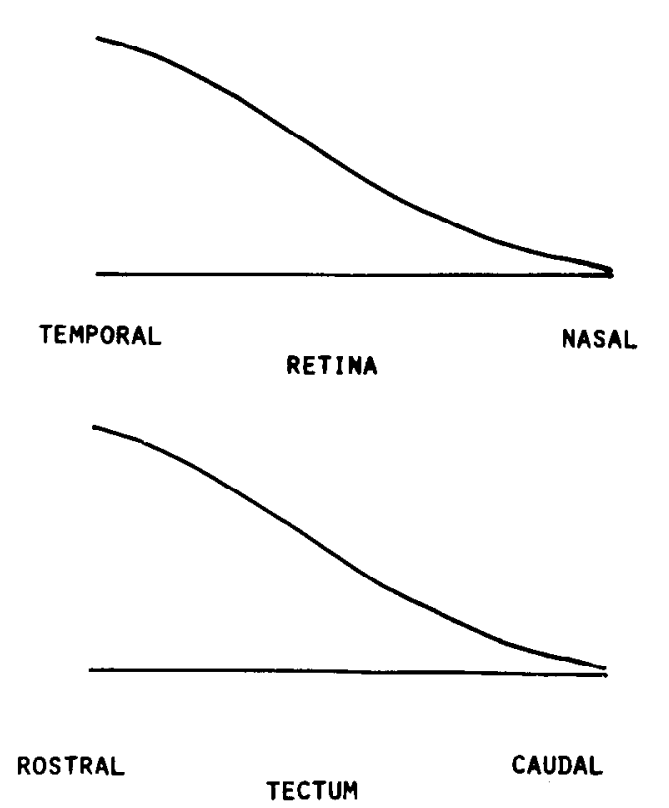

TECTUM

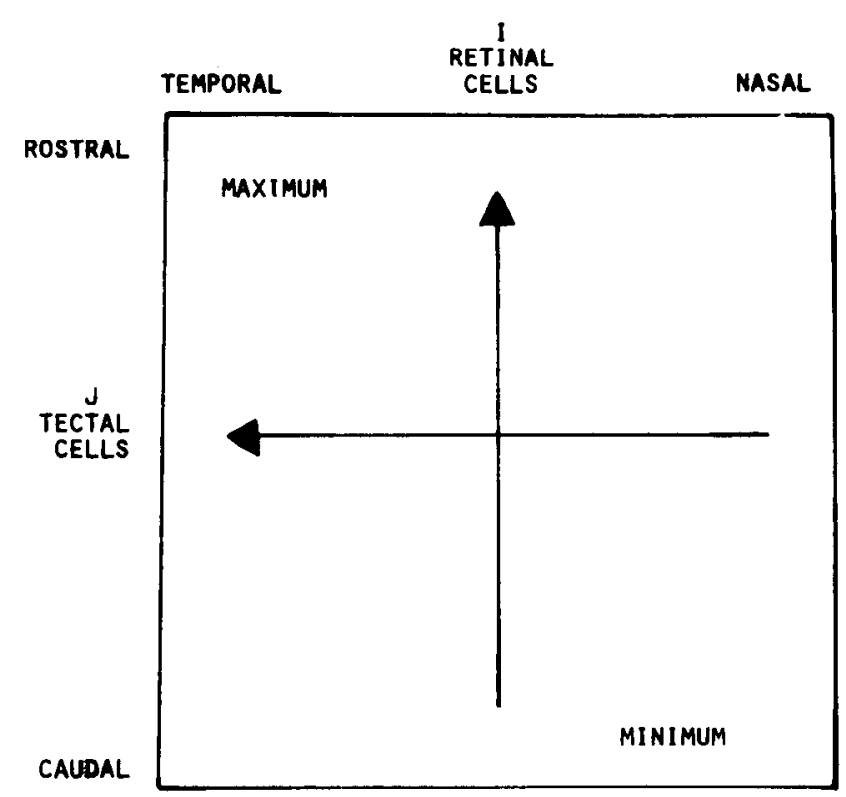

ADHESION MATRIX

Figure 1. Monotonically graded marker distributions were assumed, following equations 3 . These gradients supplied positional information to each cell and polarity to the array $(A)$. The adhesion matrix $(B)$, calculated according to equation 4 , shows maximal adhesion between cells having the highest concentration of marker.

If $a_{i}$ and $a_{j}$ are, respectively, the retinal and tectal marker concentrations, their mutual adhesion, $c_{i j}$, can be expressed as:

$$
c_{i j}=\xi a_{i} a_{j}
$$

where $\xi$ is a coefficient related to the binding energy or strength of individual bonds. ${ }^{4}$

A distinguishing feature of the present model is that contact adhesiveness does not change with context. This is in line with evidence against marker regulation in the retinotectal system.

Competition among retinal fibers and tectal cells. Prestige and Willshaw (1975) showed that a graded contact affinity model could generate retinotopic maps, provided there was competition among retinal fibers for tectal contacts and among tectal cells for retinal input. If the biochemical affinities are too specific, i.e., if $c_{i j}=0$

\footnotetext{
${ }^{4} c_{i j}$ can be expressed as $c^{\prime}{ }_{i j} / \tau=E_{0}$, where $\tau$ is the time constant of synaptic change, $E_{0}$ is the mean energy dissipated at the junction by correlations of background activity, and $c^{\prime}{ }_{i j}$ is the mean lifetime of the contact, approximately one-half the lifetime of a single bond times the number of bonds. This can be understood in terms of a simple bimolecular binding reaction (see Bell, 1978) with forward and reverse rate constants $k_{+} \mathrm{cm}^{2} \mathrm{sec}^{-1}$ and $k_{+} \sec ^{-1}$, respectively, taking place at a contact of surface area $s_{0} \mathrm{~cm}^{2}$ and separation $r_{0} \mathrm{~cm}$. Then $c^{\prime}{ }_{i j}$ can be expressed as:

$$
\frac{1}{2} k_{-}^{-1} \exp \left[-r_{0} f / k T\right] \frac{k_{+}}{k} \cdot s_{0} a_{i} a_{j}=\xi a_{i} a_{j}
$$

where $f$ is a random force acting to break the bonds and where $k T$ is the Boltzmann energy factor.
}

for all $i \neq j$, the maps show no regenerative plasticity. Thus, to simulate the retinotectal system suitably, the adhesions must be graded as previously discussed. However, it is then necessary to introduce competition between retinal fibers for tectal contacts in order to prevent all of the afferents from synapsing with the target cell having the highest marker concentration. Competition is included in the present model by normalizing the synaptic strength matrix with respect to both pre- and postsynaptic arrays.

$$
\sum_{i} s_{i j}=n_{j} ; \sum_{j} s_{i j}=n_{i}
$$

This physically implies an inverse relation between the number of synapses that a cell makes and the average strength of each. Because of this inverse relation, all of the cells have to share roughly the same number of synapses in order for those synapses to be comparatively strong.

This interpretation of competition assumes that neurons have a limited capacity to make and maintain synapses. For the ganglion cell, this may be understood as a limit to the spatial extent of an axonal arbor or to the amount of neurotransmitter that the cell can synthesize. For the tectal cell, it implies a limited somatodendritic area or amount of receptor protein available for receiving connections. Although direct evidence for these assumptions is not available for fish or frogs, indirect evidence from the characteristic branching patterns of retinal ganglion cell axons and tectal cell dendrites is consistent with a relative uniformity in the number of connections shared by these cells. Histological and electrophysiolog- 
ical evidence (Lazar and Szekely, 1969; Devor and Schneider, 1975; George and Marks, 1974) indicates that a single retinal fiber contacts many tectal cells and that a single tectal cell is contacted by many retinal fibers. A study of the cytoarchitectonics of the tectum suggests that a uniform many-to-many matching is characteristic of the rostrocaudal axis.

The logistics of the model. An array of fibers corresponding to the retinal nasotemporal axis $\left(i=1,2, \ldots N_{r}\right)$ and another array of cells corresponding to the tectal caudorostral axis $\left(j=1,2, \ldots N_{t}\right)$ are assigned marker concentrations in accord with equations 3 (see Fig. 1). Contact adhesiveness for each $i-j$ combination is calculated from equation 4 , thus generating a matrix of $c_{i j}$ values. A randomly chosen local cluster of retinal fibers is activated by setting $r_{i}-1=r_{i}=r_{i}+1=1$. Tectal activity then is calculated from equation 1 , given an initial distribution of the synaptic strengths, $s_{i j}^{0}$. Three different initial distributions have been used with equal success: $s_{i j}^{0}=0$, uniformly small, or randomly distributed. In the following calculations, $s_{i j}^{0}=0.05$ for all $i, j$ values.

Changes in synaptic strength are then calculated from equation 2. A synaptic strength is calculated for all possible $i-j$ combinations, although many are 0 or are set to 0 if they are below a low level threshold. The $s_{i j}$ matrix is normalized according to equations 5 . The two normalization conditions are not satisfied simultaneously. Normalization is performed first with respect to the presynaptic array and then with respect to the postsynaptic array. Another cluster of retinal cells is activated then, tectal activity is recalculated using the new values for the synaptic strengths, and the process is repeated. The algorithm is autocatalytic in that contacts of highest adhesiveness are most sensitive to synchronous retinal and tectal activity; consequently, their synaptic strengths increase most rapidly. (See "Mathematical Appendix" for details of the programming of the model and the parameter set used.)

\section{Results of the Model}

The patterns of synaptic strength that result from the model's calculations are displayed as $N_{r} \times N_{t}$ matrices (see Fig. 2). The area of each elementary square in the display is directly proportional to the symaptic strength. Figure 3 shows a representation of the normal retinotectal map. The temporal visual field projects to nasal retina and then to caudal tectum; the nasal visual field projects to temporal retina and then to rostral tectum. One dimension of this map can be expressed in matrix form, as in Figure 2, with the pattern of large synaptic strengths lying along the diagonal.

Normal development. As indicated in Figure 4, the model replicated the normal retinotectal map. Moreover, a very small gradient of adhesion was sufficient to organize the map. For example, the difference between the maximum and minimum $c_{i j}$ could be as small as $5 \%$ of $c_{i j \max }$. This is well within the range of experimental estimates of the adhesive preference on the part of retinal halves for the tectal halves to which they normally project (Barbera et al., 1973; Barbera, 1975; Balsamo et al., 1976).

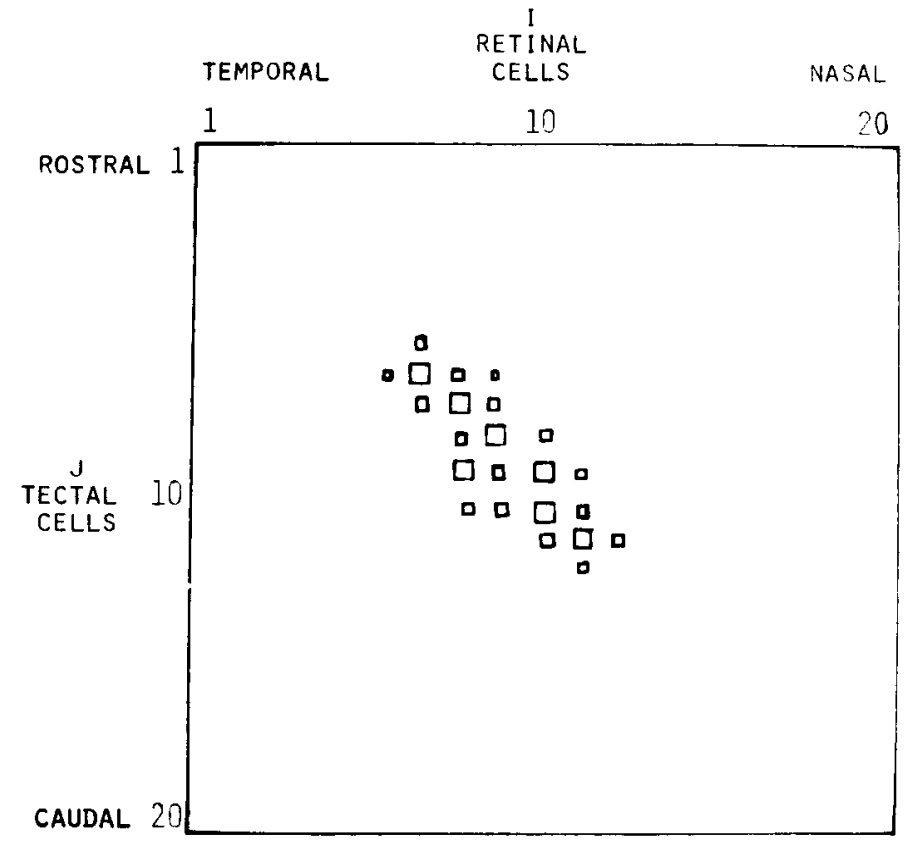

SYNAPTIC CONDUCTIVITY MATRIX

Figure 2. The synaptic strength (calculated from equation 2) of all retinotectal cell pairs is displayed in a matrix. The area of the square at the $i-j$ intersection represents the strength of the synapse between the $i$ th retinal fiber and $j$ th tectal cell. The normal retinotectal map is represented by large squares along the matrix diagonal.
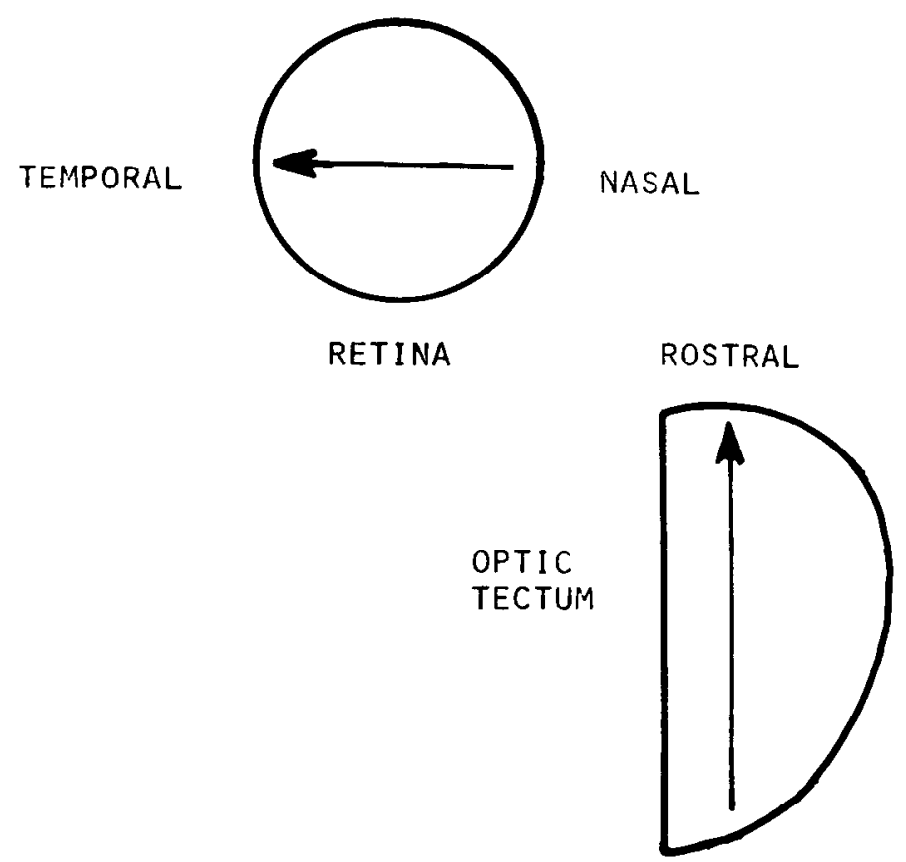

CAUDAL

Figure 3. In the normal retinotectal map of frogs and goldfish, temporal retina projects to the rostral tectum; nasal retina projects to the caudal tectum. Each retina projects to the contralateral tectum. 


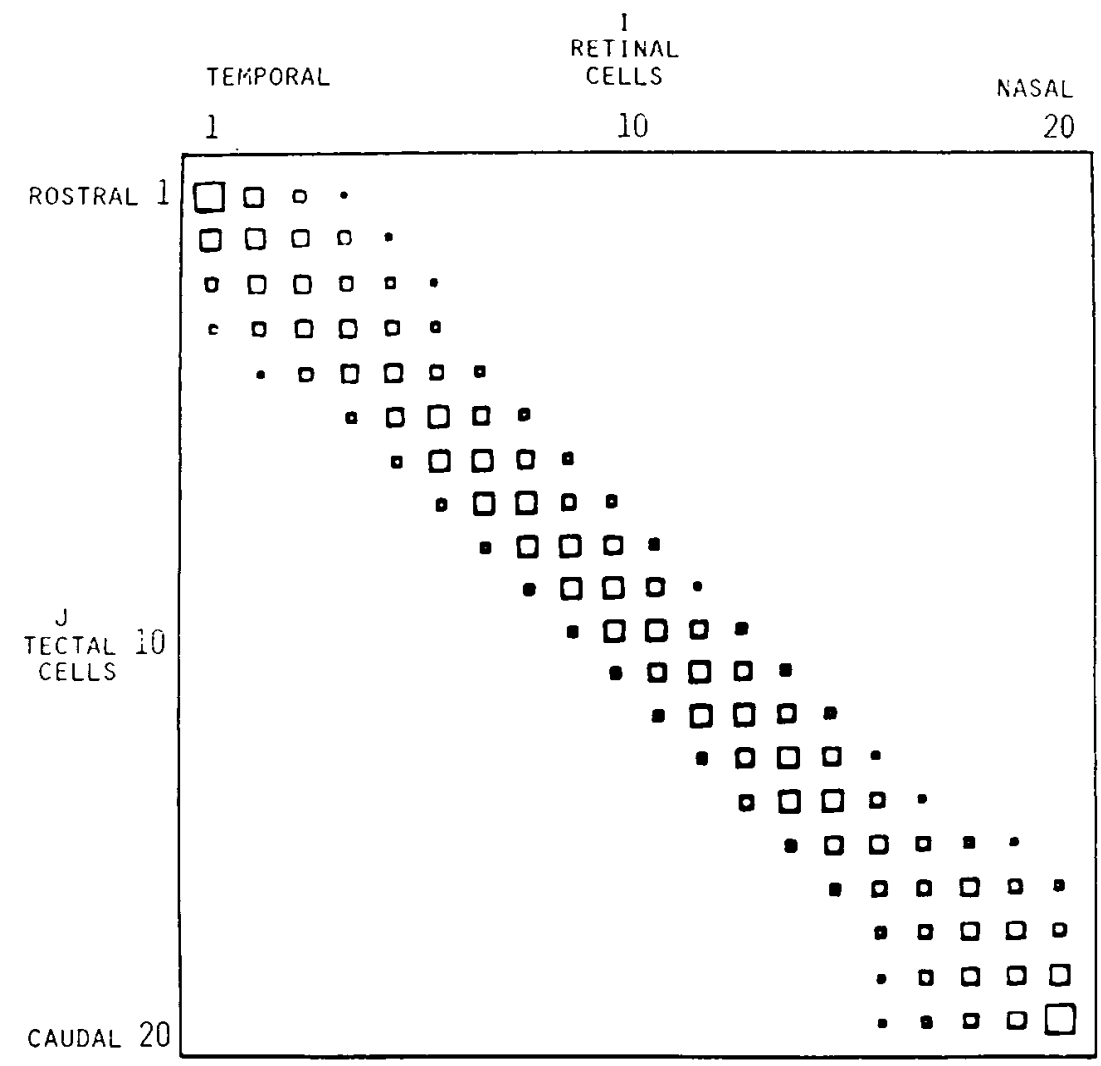

Figure 4. The normal one-dimensional retinotectal map was simulated by the model using initial synaptic strength conditions of $s_{i j}=0,0$ to 0.05 or $x$, where $x$ was a random number in the range of $[0.01,0.1]$.

An important conclusion from the present study is that the putative marker gradients can be very small, and therefore very difficult to detect experimentally, and yet still be effective organizers of the retinotectal map. In model calculations, the magnitude of the gradient determined the number of iterations required to form the map: the larger the gradient, the fewer the number of iterations required.

Another interesting feature of the model is that adhesion differences need not be ubiquitous in the retina and tectum. If only a fraction of retinal fibers and tectal cells were chemically specified, such that a small ordered patch of the map formed (see Fig. $5 A$ ), then the rest of the map "nucleated" around the patch without the need for specificity in the remainder of the system (Fig. $5 B$ ). This resulted from the nearest neighbor correlations in retinal and tectal activity.

It is known that the retina and tectum differ in their patterns of growth (Straznicky and Gaze, 1971, 1972; Gaze et al., 1974). The retina grows in rings, adding cells to its circumferential margin, whereas the tectum grows asymmetrically, adding crescents of cells to its caudomedial border. Accounting for map formation subject to this differential growth was not a difficulty for the present model. Newly added cells could be labeled with markers in accord with equations 3 or not be labeled at all. In either case, a complete map formed. In addition, as will be demonstrated in the simulation of partial tectal ablations, the retinal fibers could slide from one tectal cell to another, which allowed the retinotectal map to reorga- nize in accord with the differential size (or growth) of the retina and tectum.

Regeneration and the effects of debris. In fish and amphibians, if the optic nerve is cut or crushed, a normal retinotectal map regenerates. This effect .can be replicated by the model. The lesion was simulated by setting all synaptic strengths to 0 (or to 0.05 ) following the development of a normal map and then iterating the algorithm until a new map formed.

Regeneration may differ from development in that a retinal imprint or debris from prior innervation may be left on the tectal cells. Other models have incorporated this possibility (von der Malsburg and Willshaw, 1977; Willshaw and von der Malsburg, 1979) to account for those regeneration studies which clearly indicate labeling of the once-innervated tectum (Sharma and Gaze, 1971; Yoon, 1975a, b; Rho, 1978; Schmidt, 1978). In postulating intrinsic tectal markers, the present model required neither retinal imprinting nor a facilitatory role for debris in order to replicate such regeneration experiments.

In principle, it is possible that debris could alter or inhibit regeneration by occluding intrinsic tectal markers. Evidence against this comes from studies in which reinnervation of the tectum is delayed for long intervals following the initial surgery until the morphological signs of debris have disappeared from the tectum (Sharma and Romeskie, 1977). The results of such experiments do not differ from those in which reinnervation is not delayed and debris is present. This suggests that debris does not have a first order effect on regeneration. 


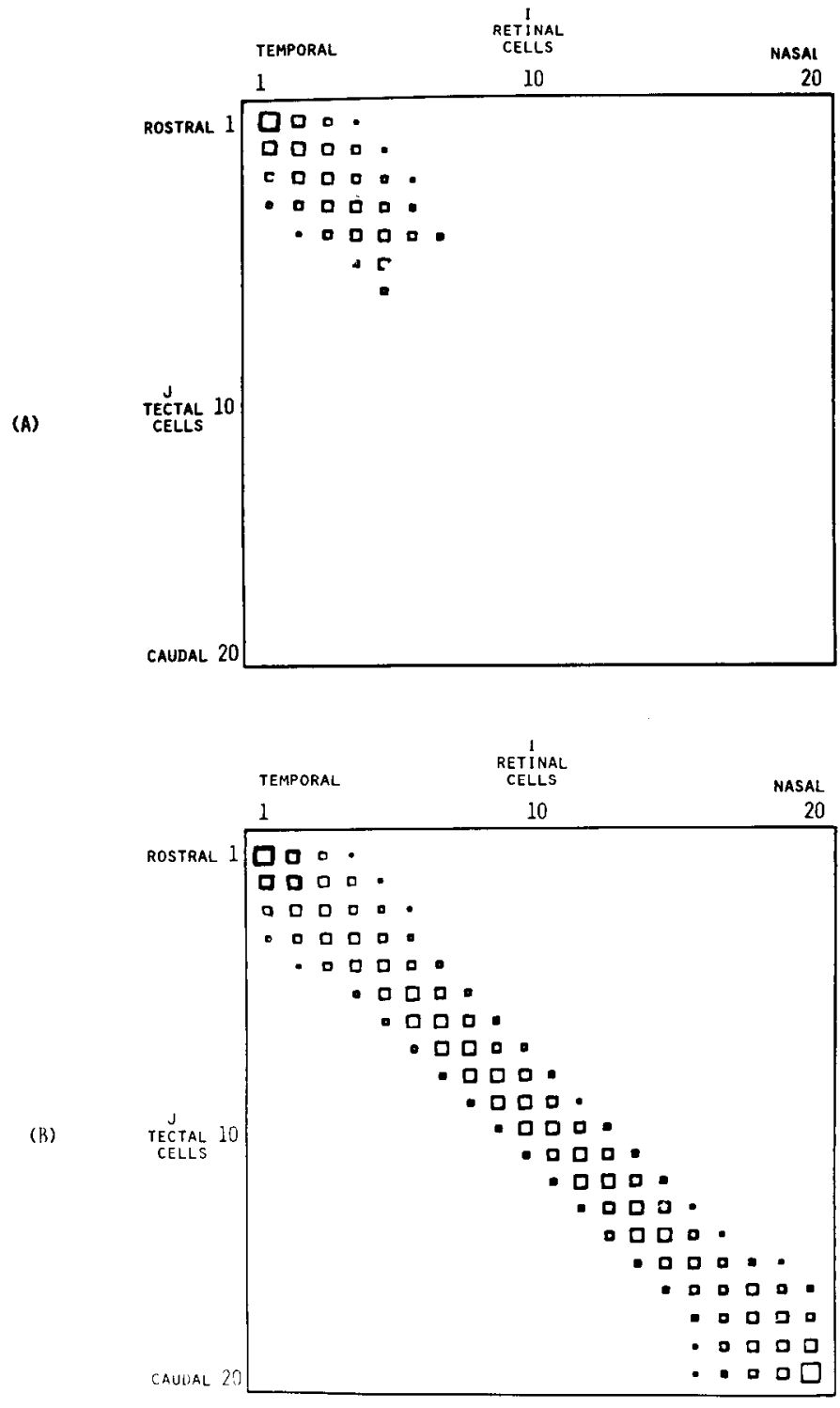

Figure 5. If only a fraction of the retinal and tectal cells were chemically specified (here, $25 \%$ ), the resultant patch of retinotopic order was sufficient to organize the rest of the map. The starting conditions in $A$ gave rise to the ordered connections in $B$ without assuming any markers in the remaining retina or tectum.

Expansion. A well documented example of the plasticity of retinotectal connections is that of the expansion of the retinotectal map in goldfish following partial retinal ablation (Sharma and Gaze, 1971; Horder, 1971; Yoon, 1972a; Schmidt et al., 1978; Schmidt, 1978). This is shown in schematic form in Figure 6. At first, the regenerated map is confined to the appropriate part of the tectum. However, after 4 to 6 weeks, the map expands over the entire tectal surface. This occurs after the optic nerve is cut or crushed or left intact from surviving retinal fragments.

Such conditions were simulated in the model by pairing a full array of tectal cells with a half array of retinal fibers. The temporal half of the marker profile as calculated for a full (normal) retina was used in the expansion simulations.

Three partial retinal ablation situations were consid-

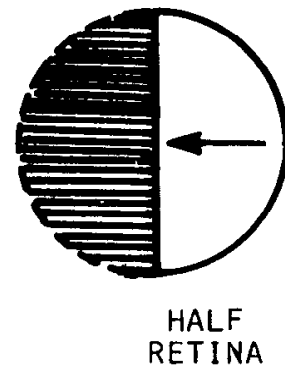

NASAL

RETINA

ROSTRAL

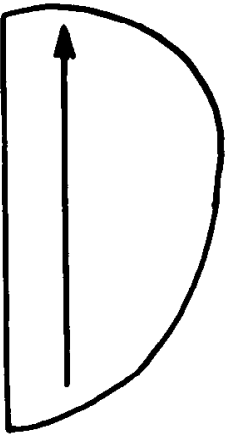

CAUDAL

Figure 6. In goldfish, partial retinal ablation followed over a sufficiently long time course results in an expanded retinotopic representation of the retinal fragment over the entire tectal surface.

ered, corresponding to (1) development, (2) regeneration following optic nerve section, and (3) regeneration in the presence of an intact half-optic nerve, involving modification of existing synapses. Figure 7 shows the model's simulations of these three situations. Expansion occurred very quickly in the first two cases (Fig. $7 \mathrm{~A}$ ) but required more iterations of the algorithm in case 3 involving an initially intact half-optic nerve. Figure $7 B$ shows the starting conditions of this latter case from which an expanded map developed (Fig. 7C).

It should be emphasized that expansion was simulated without assuming any changes of the marker concentrations. The change of context, that is, the change in the relative sizes of the retinal and tectal arrays, was sufficient to re-pattern the connections between them.

Compression. The map compression observed in the projection of an intact retina onto a half-tectum (Gaze and Sharma, 1970; Yoon, 1971, 1972a, 1976) has been cited as evidence against chemospecificity. In the model presented here, however, compression was obtained in all simulations of those contexts in which it has been observed experimentally. The same situations as described for expansion were simulated for compression, with the only change being that a full retinal array was paired with a half tectal array (the rostral half of the normal marker distribution was used). Figure 8 depicts the experimental conditions and Figure 9 summarizes the model's calculations. Figure $9 A$ shows the model's results for the case of development or regeneration following optic nerve section. An intact half-optic nerve also was simulated as a starting condition (Fig. 9B) and the model eventually produced a compressed map.

Compressed and normal retinal projections have been obtained alternatively following insertion and removal of 


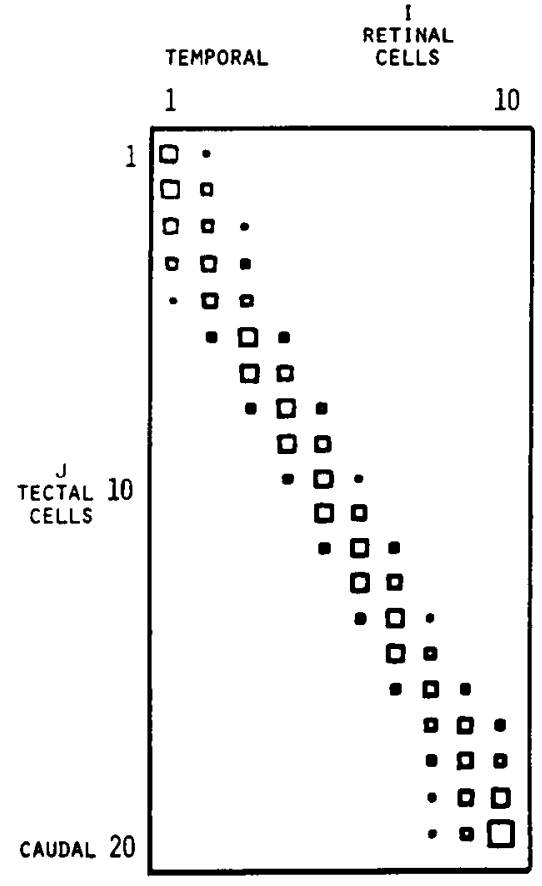

(A)

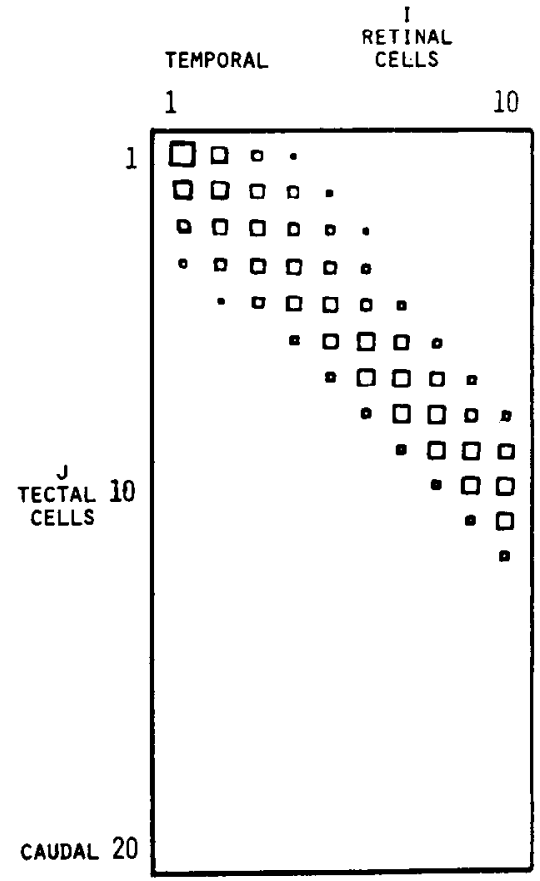

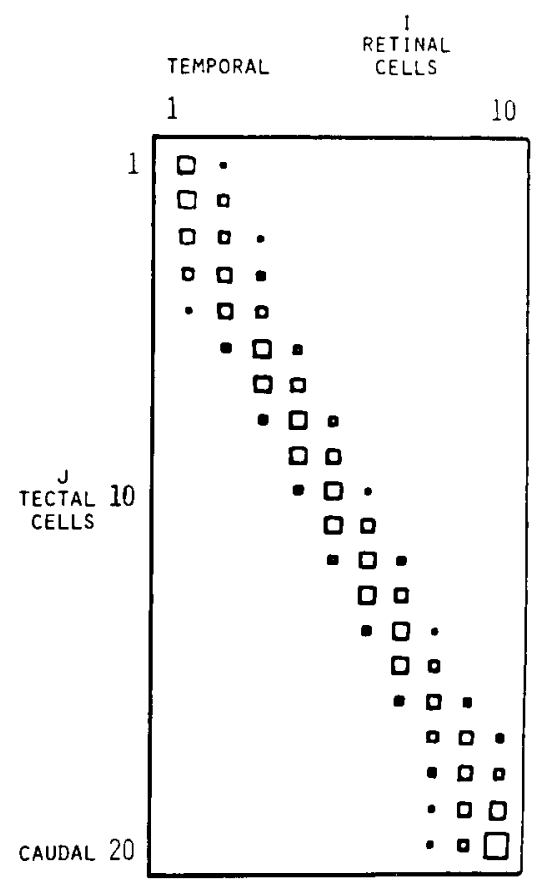

(B)

$(C)$

Figure 7. The expansion of the retinotectal map, modeled as a reduction in the size of the retinal cell array, was simulated by the model. $A$, Simulation of development or regeneration following total optic nerve section, yielding an expanded map in less than 100 iterations. The initial synaptic strength matrix consists of small, randomly distributed values. $B$, Initial synaptic strength matrix simulating regeneration in the presence of an intact half-optic nerve. $C$, The final map achieved under such an initial condition. In both cases $(A$ and $C$ ), expansion was achieved without assuming any changes in the marker concentrations.

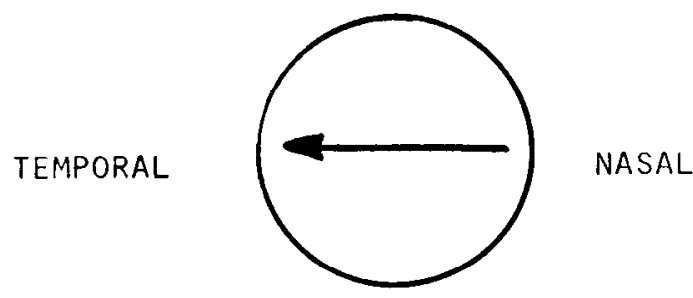

RETINA

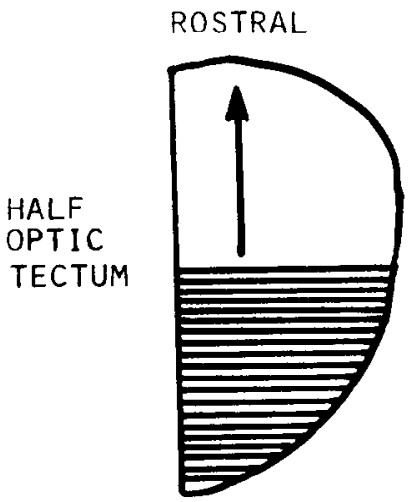

Figure 8. An orderly compression of the retinal projection onto the remaining tectum is observed in goldfish which have undergone partial tectal ablations.

an impermeable barrier in the tectum (Yoon, 1972b; Edwards and Jacobson, 1979). These effects can be replicated with the model simply by changing the relative sizes of the retinal and tectal arrays, thus demonstrating again the importance of context in determining the retinotectal map.

Mismatch. Experiments have been reported in which partial retinal and tectal ablations are performed in the same animal (Horder, 1971; Yoon, 1972a; Meyer, 1978, 1979). Under conditions where inappropriately paired retinal and tectal halves are spared, for example, nasal retina and rostral tectum, an orderly map regenerates. If all of the pre-existent connections are severed, the regenerated projection is of normal polarity, i.e., the most temporal part of the nasal hemi-retina projects to the most rostral part of the hemi-tecturn. Figure 10 shows a simulation of this experiment. Both the retinal and tectal arrays were halved such that halves which do not normally connect were spared. The $s_{i j}$ matrix was, for obvious reasons, 0 except in the quadrant corresponding to the spared hemi-arrays. Normally the synaptic strengths in this quadrant are 0 (as in Fig. 4). In this mismatch situation, however, an orderly projection of normal polarity resulted.

Graft translocation. Translocation experiments, which involve polarity-preserving exchanges of position of two tectal grafts, have produced somewhat conflicting results. In most cases, tectal transplants produce translocations in the projection. Retinal fibers connect to their normal tectal targets and, if such targets are in abnormal locations, discontinuities in the map are produced as shown in Figure 11. In other cases, particularly if the projection to untranslocated tectal regions is left intact, a normal map is obtained (Sharma and Gaze, 1971; Yoon, 1973; 

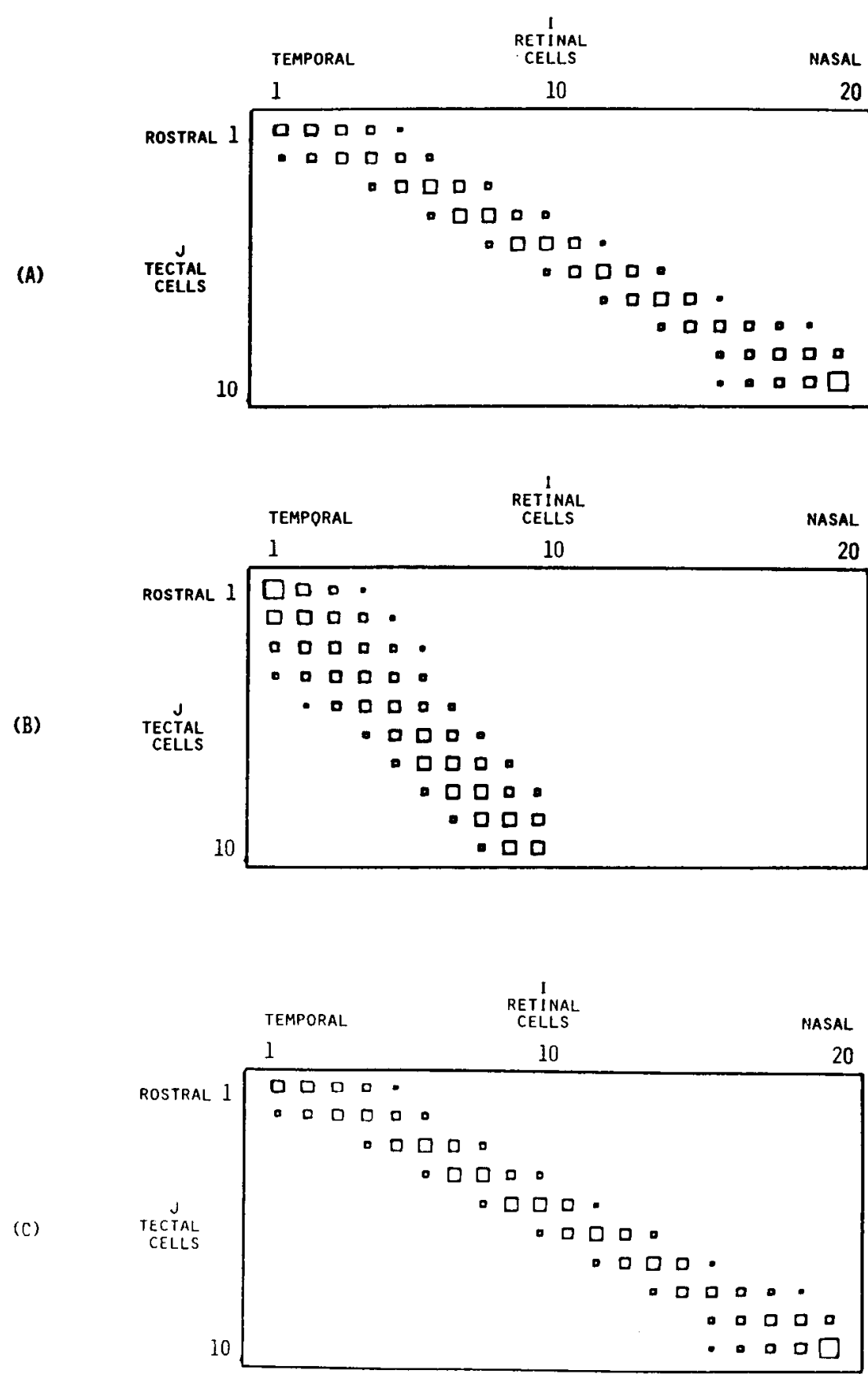

Figure 9. Partial tectal ablation was modeled as a reduction in the size of the tectal cell array. Compression was simulated without assuming any changes in the marker concentrations. The simulation of development or regeneration following optic nerve section yielded a compressed map in less than 100 iterations $(A)$. Regeneration in the presence of a partially intact optic nerve $(B)$ required more iterations (700 to 800$)$ of the algorithm before a compressed map emerged $(C)$.

Levine and Jacobson, 1974; Jacobson and Levine, 1975a, b; Martin, 1978).

Translocation was modeled as the exchange of two subsets of marker-labeled tectal cells (see Fig. 11A). Polarity (i.e., slope of marker distribution) was preserved. Three differing initial conditions were investigated, corresponding to (1) development, (2) regeneration following optic nerve section, and (3) regeneration in the presence of an intact projection to non-translocated tectal regions.
The maps formed under such conditions resulted from the interplay of conflicting influences: (1) chemospecificity, which tended to produce maps sensitive to any changes in marker distribution, and (2) the tendency to nucleate continuous projections as discussed earlier. The relative influence of these two factors was varied in the model, giving rise to two different maps as shown in Figure 12. Chemospecific influences dominated and discontinuous maps were formed following translocation, 


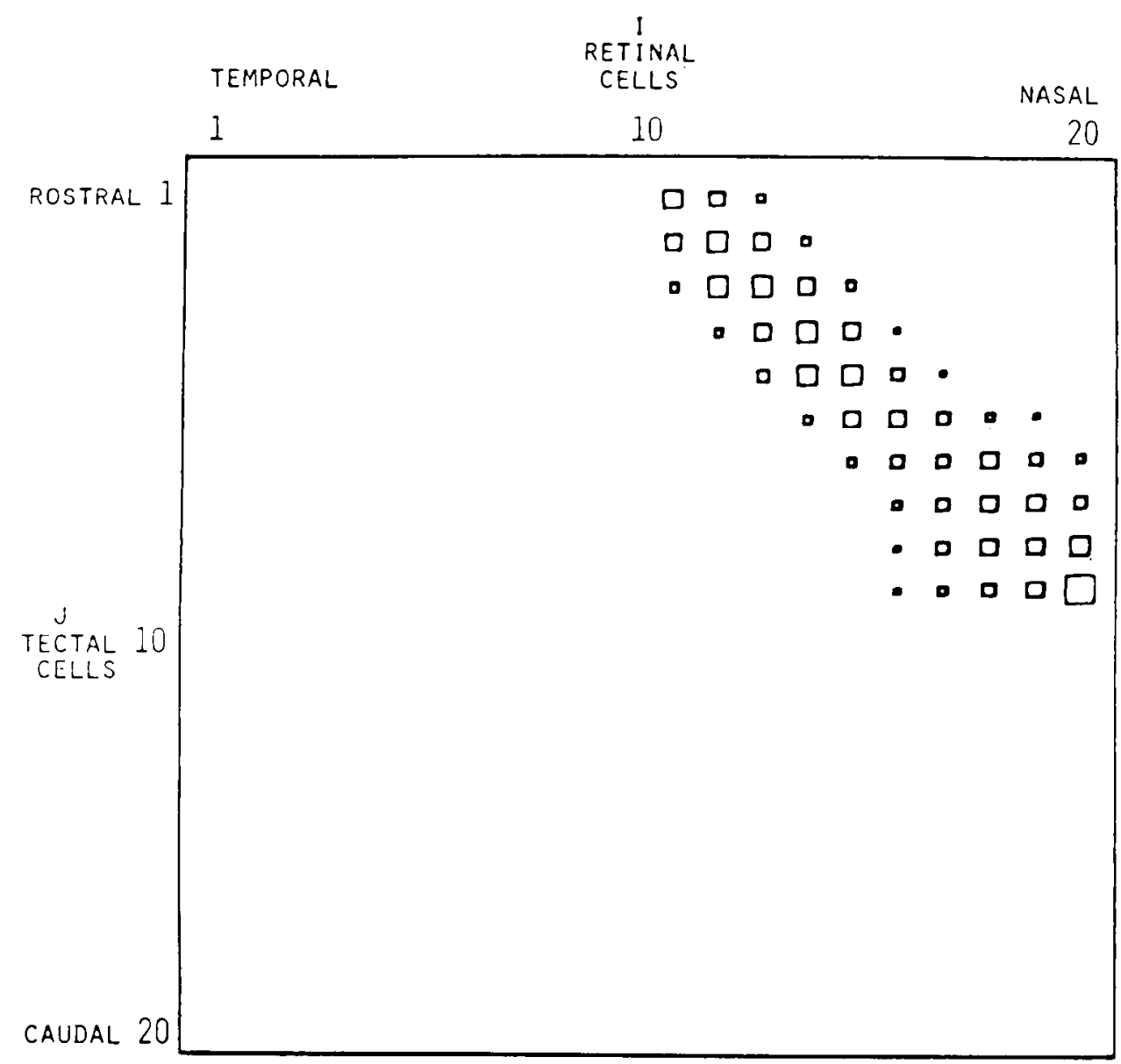

Figure 10. The mismatch experiment was modeled by halving both the retinal and tectal cell arrays. The model simulated the formation of a retinotopic map between the remaining inappropriate retinal and tectal halves. Here, the caudal half-tectum and the temporal half-retina have been removed. The most temporal part of the nasal half-retina still mapped rostrally; the nasal part mapped most caudally.

provided that initially all synaptic strengths were small ( 0 or 0.05 ; Fig. $12 A$ ). This result is consistent with experiments in which the optic nerve is sectioned and the effects of debris can be ruled out (Martin, 1978). If there were strong prior connections (i.e., large initial synaptic strengths) as in case 3 (Fig. $12 B$ ), then nucleation from these connections occurred, resulting in a continuous map (Fig. 12C). This is consistent with the finding of continuous maps when the optic nerve is not sectioned (Sharma and Gaze, 1971; Jacobson and Levine, 1975a).

Graft rotation. There is another series of experiments involving grafts, the results of which are similar to those following graft translocation. These are graft rotation studies, in which whole retinae, tecta, or tectal fragments are rotated by $180^{\circ}$. In the context of the present onedimensional study, this means polarity reversal of the marker distributions.

Rotations have been performed at both early and late stages in development. The various results to be replicated are as follows: (1) retinal rotation done well before the outgrowth of the optic nerve results in the development of a rotated map in frogs (Hunt and Jacobson, 1972a, b, 1974; Gaze et al., 1979). (2) Retinal rotation (and optic nerve section) performed after the initial map development results in regeneration of a rotated map (Sperry, 1949). (3) Rotation of previously innervated tectal grafts results in rotated maps in goldfish (Sharma, 1969; Sharma and Gaze, 1971; Yoon, 1973, 1975b). (4) Rotation of previously innervated tectal grafts in frogs sometimes produces rotated maps and other times produces normal maps (Levine and Jacobson, 1974; Jacobson and Levine, 1975a, b). (5) Rotation of "naive" tecta which have not been innervated previously produces rotated maps (Chung and Cooke, 1975; Straznicky, 1978).

Figure 13 summarizes simulations of these experiments. Rotation of the entire retinal or tectal array produced a rotated map (Fig. 13B). This was the case for either development or regeneration. If only part of the retinal or tectal arrays were rotated (Fig. $13 C$ ), initial conditions were critical in determining map polarity. The results paralleled those for translocation in that there was competition between the chemospecific effects and nucleation from the existing order. In the simulation of graft rotation plus total severing of the optic nerve such that initially all $s_{i j}=0$ (or 0.05 ), chemospecific effects dominated and a discontinuous map resulted with reversed polarity in grafted regions (Fig. 13D). Conversely, if there were initially large synaptic strengths corre- 

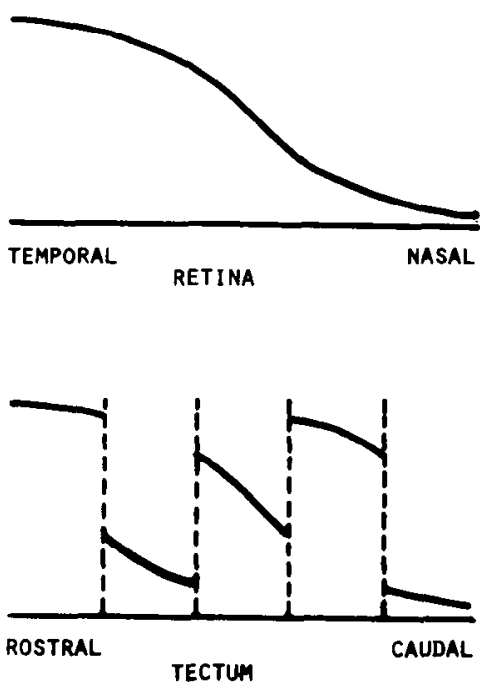

(A)
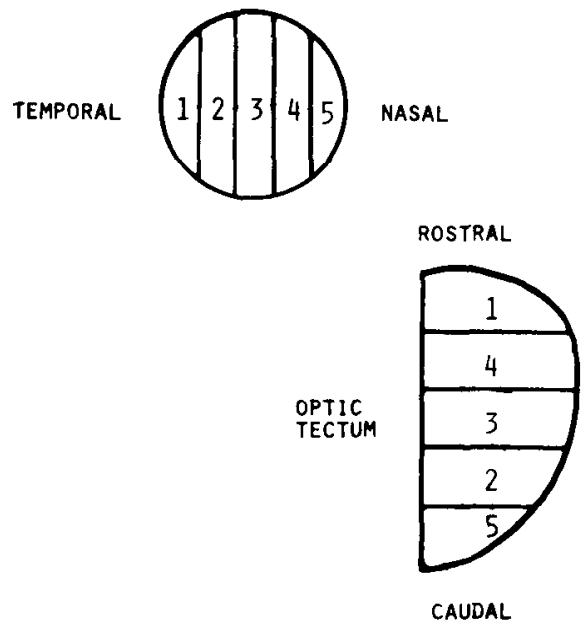

(B)

Figure 11. Tectal graft translocation can be modeled as an exchange of position of two sets of tectal markers with their polarity preserved $(A)$. The schematic in $B$ shows a discontinuous map respecting the graft translocations, which is the result most frequently obtained in these experiments. In some cases, particularly if the optic nerve to the untranslocated regions is left intact, a normal map is observed.

sponding to initial connections from an intact partial optic nerve (Fig. 13E), a continuous map nucleated off the prior connections (Fig. 13F).

Compound eye experiments. Another series of experiments which can be replicated by the present model involves compound eyes. The compound eye is formed by placing two equivalent hemi-retinae from two eyes in the same eye socket. The projection from such an eye to the contralateral tectum has been described as a double expansion as shown in Figure 14 for a frog double nasal eye (Gaze et al., 1963, 1965). This result can be replicated by the model with the assumptions that the double nasal retina contains a mirror-symmetric marker distribution characteristic of a nasal half-retina and that the two halfretinae form connections independently (i.e., that the ganglion cell activity is not correlated between the retinal halves). Figure 15 shows the results obtained with these assumptions. Two expanded maps were generated as observed in experiments.

\section{Discussion}

Comparison with previous models. The model presented here uniquely combines chemospecific markers with modifiable synapses. It differs from previous models in that it postulates a fixed distribution of markers in both the retina and tectum. Such models generally have assumed that the tectum is unspecified initially. Hence, they required some extrinsic orientation information to organize the retinotectal map. In the marker induction model, for example, it is postulated that the tectum becomes specified during development as retinal fibers leave their imprint on the tectum in the form of unique combinations of diffusible markers (Willshaw and von der Malsburg, 1979). It is assumed that, during regener- ation, the tectum has such a marker memory of its prior innervation pattern. This memory is required in order to account for the results of tectal graft translocation and rotation experiments. Postulated marker mobility accounts in large part for the plasticity of connections observed in size mismatch experiments (i.e., expansion and compression). This is an example of marker regulation, an assumption against which there is considerable experimental evidence as discussed earlier.

Several lines of evidence support the assertion made in the present model that tectal labels are intrinsic and nol retinally induced. First, experiments involving rotations of virgin tecta give rise to appropriately rotated maps. When the ipsilateral optic nerve is diverted into a rotated tectum which has never received a contralateral projection, a rotated map results (Straznicky, 1978). The marker induction model can account for this finding by assuming either that an extrinsic source of orientation information also was rotated during the operation or that the naive tectum possesses intrinsic orientation information in the form of a marker gradient. This latter possibility is exactly the assumption made in the present model. If intrinsic tectal markers are introduced, however, the biochemical complexity of the marker induction model is unnecessary.

A second line of evidence against the marker induction model comes from tectal graft translocation studies. As discussed earlier, in most cases, fibers can relocate their original tectal targets, despite the latter's aberrant positions. These experiments have been done only after initial map development. However, the results of translocation experiments are independent of the nature of the initial map. Even if the tectum originally receives a surgically scrambled retinal projection, an appropriately translocated map results after regeneration (Hunt, 1976; 


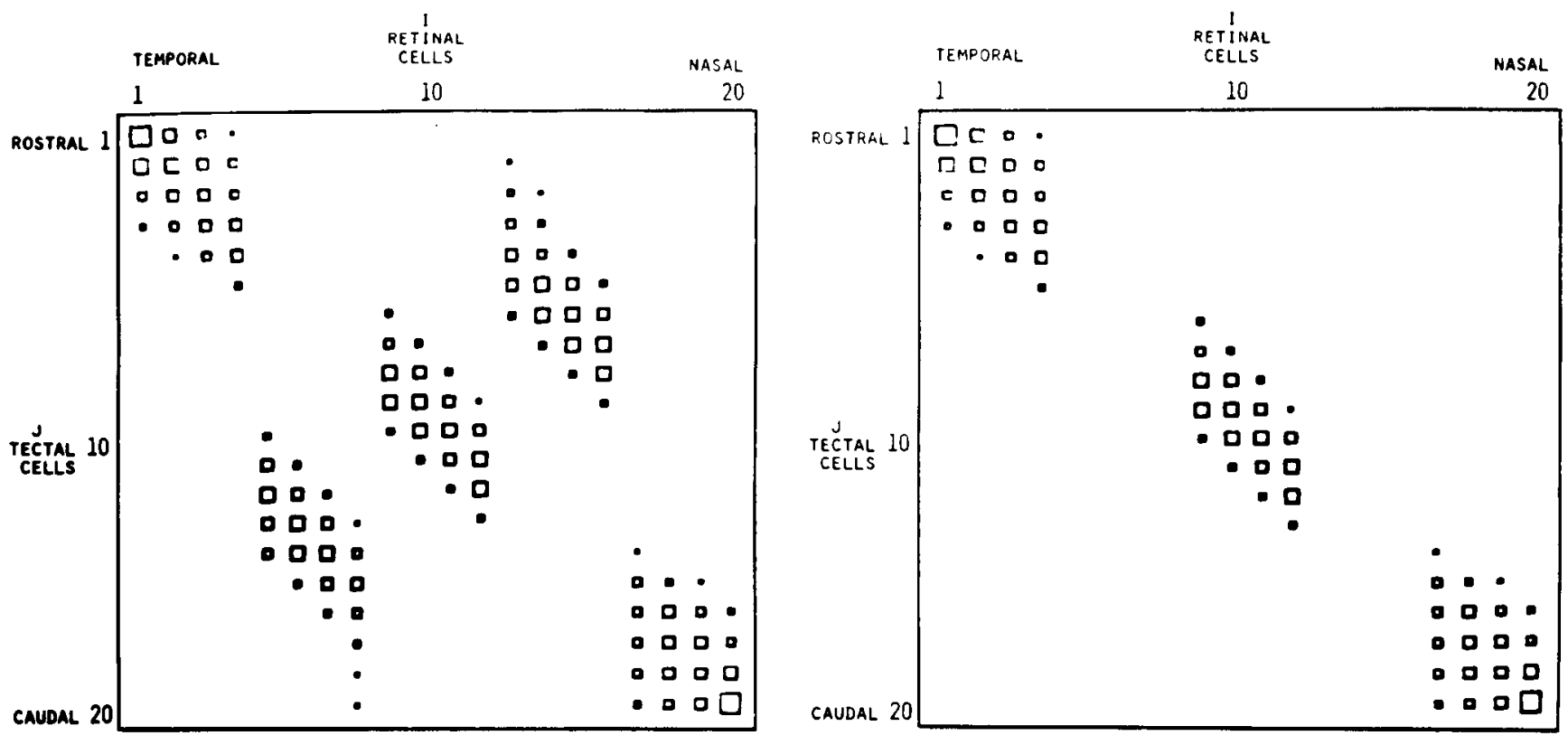

(A)

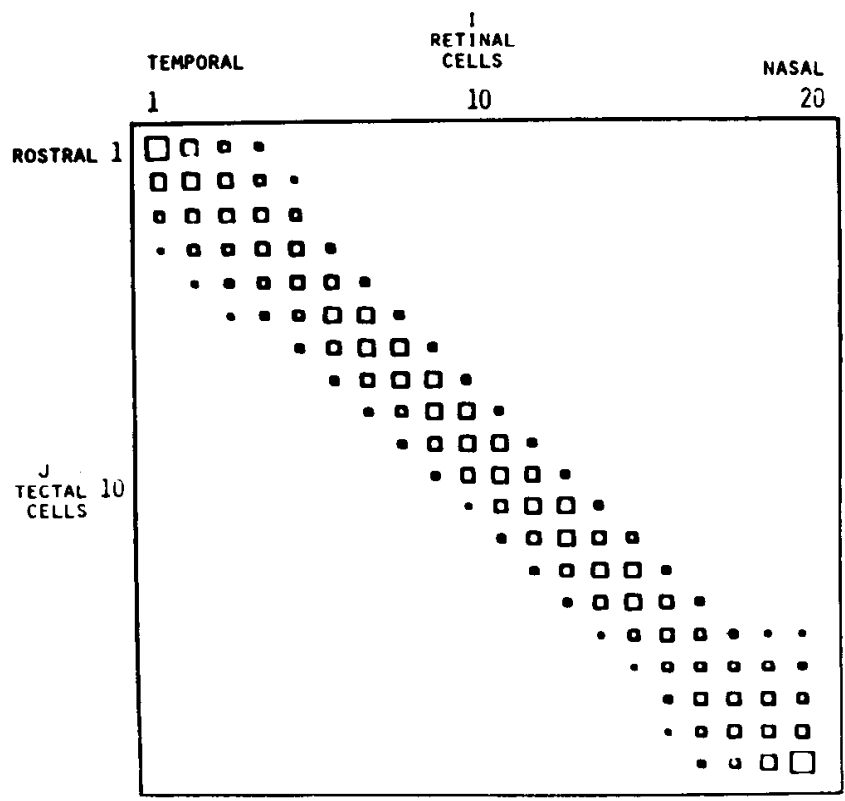

(c)

Figure 12. Following tectal graft translocation, a discontinuous map $(A)$ was obtained with the model, assuming no initially strong synapses (corresponding to the development or regeneration following optic nerve section). If the optic nerve to the untranslocated regions was left intact $(B)$, a normal map resulted $(C)$.

Fraser and Hunt, 1980). The marker induction model, which assumes that, during regeneration, the tectum bears an imprint of what it "saw" during development, cannot account for this result.

A final consideration which speaks against the involvement of retinal imprinting in the information of visual projections is that the retinotectal map is the first of a series of visual maps which preserve retinotopicity. It has been found that the tectum is capable of making appropriate connections with other visual areas in the absence of retinal input (Constantine-Paton and FerrariEastman, 1979). Two conclusions may be drawn from 

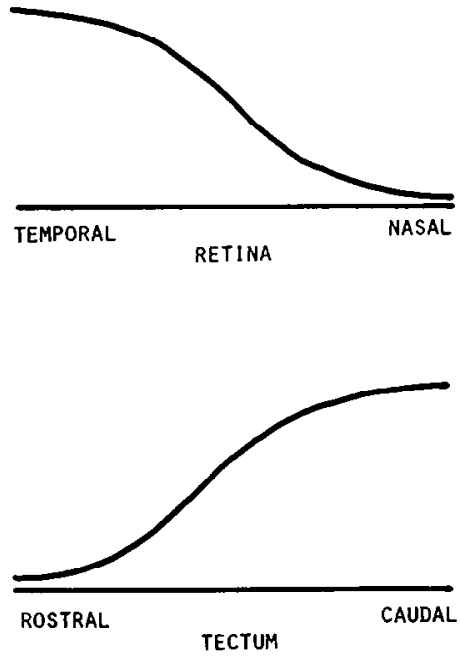

(A)
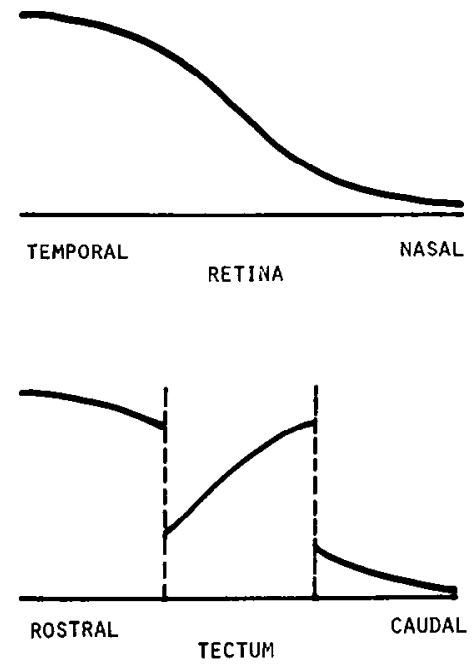

(C)

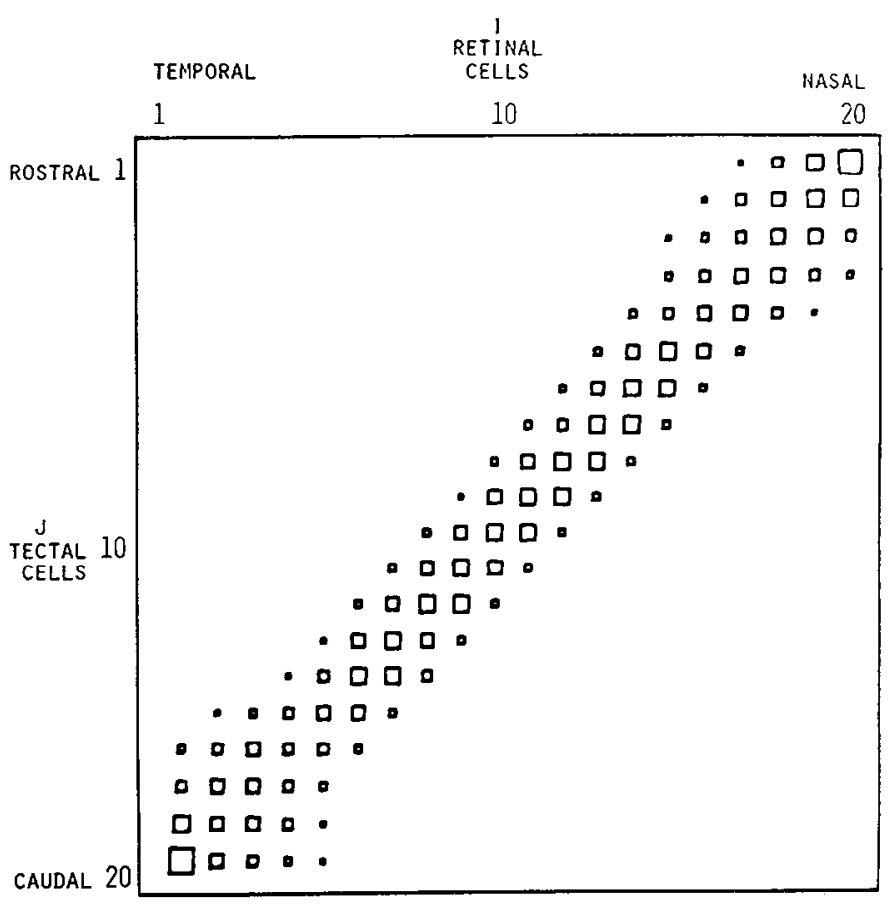

(B)

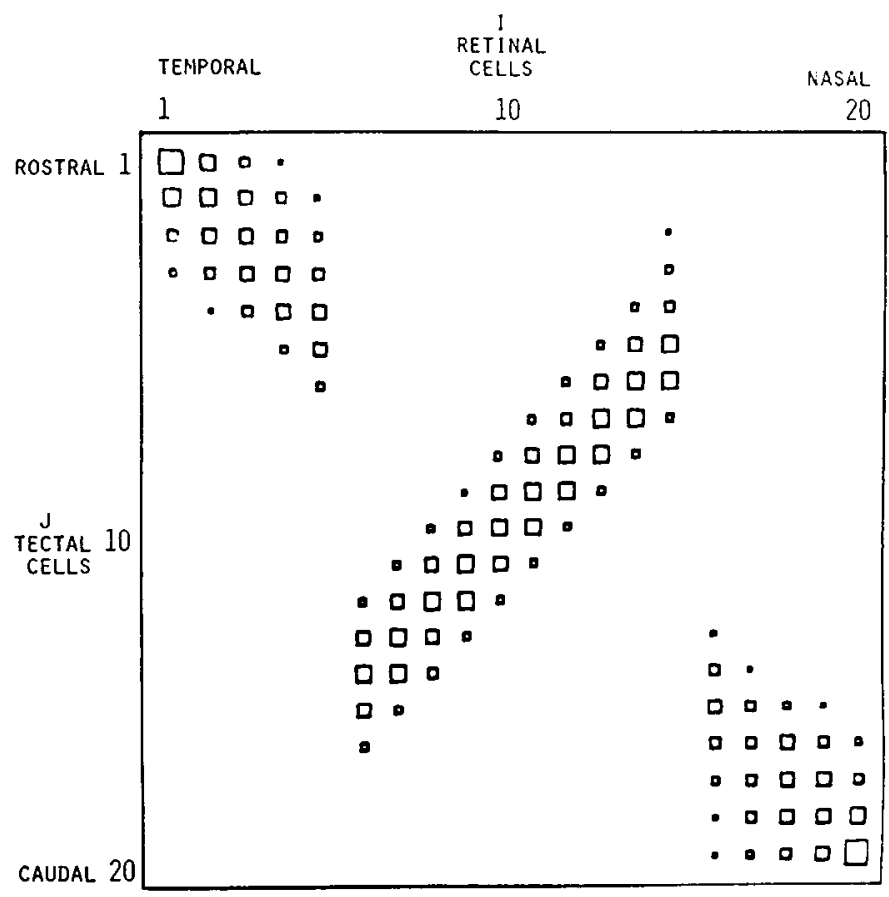

(D)

Figure 13. Retinal or tectal graft rotations were modeled as a reversal of the marker distribution of the rotated tissue. $A$ shows this reversal simulating the rotation of the entire tectum and $B$ shows the resultant map. If only part of the tectum (or retina) was rotated $(C)$, competing forces were involved in the formation of the map. If there were initially no strong synapses (i.e., following optic nerve section), chemospecific forces dominated and the result was a discontinuous map respecting the graft rotation $(D)$. 

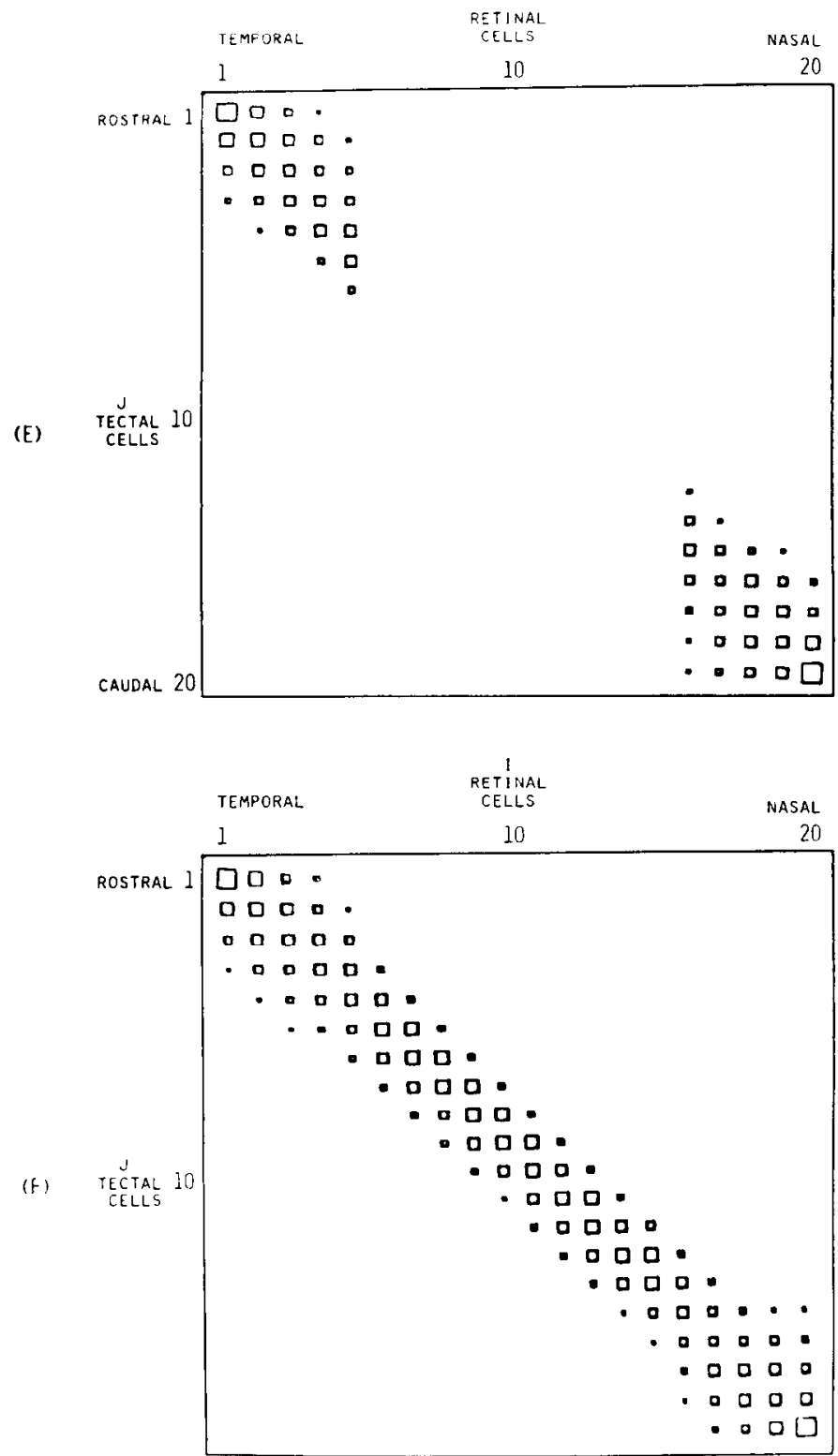

Figure 13. Continued. If, initially, there were strong synapses $(E)$, then the tendency to nucleation dominated and $(F)$ a continuous map resulted.

this observation. (1) Tectal cells do not require retinally induced markers in order to make appropriate central connections. (2) Even if such markers are transmitted, they are not involved in the process by which tectal fibers make central connections.

The best evidence for intrinsic retinal markers comes from eye rotation studies in which rotated retinotectal maps are found. Conceivably, evidence for intrinsic tectal markers could come from rotations of naive tecta by studying their projections to more central areas. It seems unlikely that, in the sequence of visual maps, only the first retinal stage is intrinsically labeled, or alternatively, that retinal labels can organize the entire sequence of maps.

The present model focuses on the importance of interactions between retinal and tectal cells in the formation of the projection between them. Other models have incorporated the postulated order retained or established among retinal fibers enroute to the tectum, that is, bundle order (Bunt and Horder, 1977; Horder and Martin, 1978a, b). Retinal fiber-fiber interactions as well as pathway guidance also have been suggested as influences on the retinotectal map. Mostly these ideas have not been expressed in computational models; it is therefore difficult to evaluate their explanatory power. One exception however, is the "arrow" model (Hope et al., 1976) which tested the extent to which retinal neighbor relationships can account for the retinotectal projection. However, the arrow model cannot replicate graft translocation and rotation experiments. Maintained retinal neighborhood relationships cannot give rise to the experimentally observed map discontinuities. Indeed, it is impossible to account for such discontinuities (as shown in Figs. $12 \mathrm{~A}$ and $13 D$ ) without positing a critical interaction between retinal fibers and tectal cells.

A second difficulty in positing the maintenance of neighbor relationships as the principle organizer of the retinotectal map is that neighbor relationships do not, in fact, seem to be maintained. Neuronal tracing (with horseradish peroxidase) and autoradiographic studies of order within the optic nerve and tracts of a number of species indicate that fiber neighborhood relationships are not strictly preserved (Horton et al., 1979; Scholes, 1979; Mason et al., 1979; Rusoff, 1980). Some evidence indicates a gross reordering of optic fibers; other data suggest a general disordering. In the frog, it is still unclear whether there is order in the optic nerve at all. None of the data is consistent with a simple maintenance of fiber neighbor relationships.

It is unlikely that an incoming retinal fiber has equal access to all cells of the tectum, but it is not unlikely that it has access to many more tectal cells than it ultimately innervates in the adult animal. It is possible that, in many species, bundle order or other mechanisms which act in the deployment of retinal fibers toward the tectum may provide some constraints on the retinal projection, but chemospecific effects would seem to be necessary to produce the detailed organization and global polarity of the retinotectal map.

If bundle order or fiber-fiber interactions were incorporated into the present model, their influence would augment that due to chemospecific markers in many of the calculations. In that sense, they would obscure the power of a single marker gradient to organize the retinotectal map in various contexts. As discussed earlier, in those situations where bundle order would oppose chemospecificity (i.e., tectal graft translocations), the evidence is that the latter dominates. This is not to say that these other mechanisms are unimportant, but they are neither necessary nor sufficient to account for the range of experimental contexts simulated by the present model. There may be other contexts in which the importance of bundle order or fiber-fiber interactions is obvious. For example, experiments in which two retinae (or parts thereof) project onto one tectum provide evidence of strong interactions between retinal fibers (Bunt et al., 1979; Meyer, 1978, 1979; Schmidt, 1978). Simulations of 
experiments involving double projections may well require assumptions about order or interactions among ganglion cell axons.

A recent model proposed by Fraser and Hunt (1980)
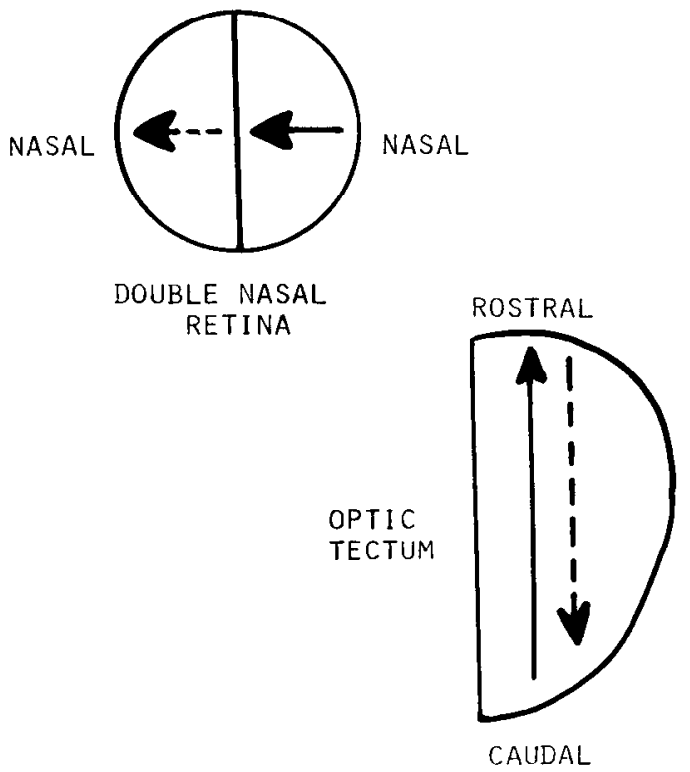

Figure 14. The classical compound eye experiments performed on frogs involved putting two retinal halves together in the same eye socket and allowing normal innervation of the contralateral tectum. A schematic for a double nasal eye is shown. The resultant map is a double expansion with the vertical midline (which is the most temporal region of this compound retina) mapping rostrally. combines interpretations of bundle order and chemospecificity in a series of rules governing the energetics of retinotectal map formation. The process of map formation is described by a free energy function which tends to a local (or global) minimum. The model, while conceptually intriguing, is impossible to evaluate in its current form in view of the omission of any parameter values. It is unclear whether a single set of parameters can cover the range of results simulated by the present model.

Chemospecificity and positional information. The model presented in this paper for the development and regeneration of retinotopic maps is based, in part, on the principle of chemospecificity. We assume that neuronal connections form as a result of selective biochemical affinities between retinal fibers and tectal cells. Chemospecificity can be related directly to another hypothesis of contemporary embryology, that of positional information (Wolpert, 1969).

The positional information hypothesis posits the differentiation of cells according to their position within embryonic tissue, following their interaction with small, diffusible molecules termed morphogens. The graded marker concentrations assumed in this model can be thought of as the products of such morphogen-triggered cell differentiation. The markers provided positional information for retinal fibers and tectal cells. The process whereby retinotopic maps are formed therefore can be interpreted as one of matching retinal positional coordinates with tectal ones. The most adhesive or "fittest" connections are selected by the process of synaptic modification, subject to the constraints imposed by competition.
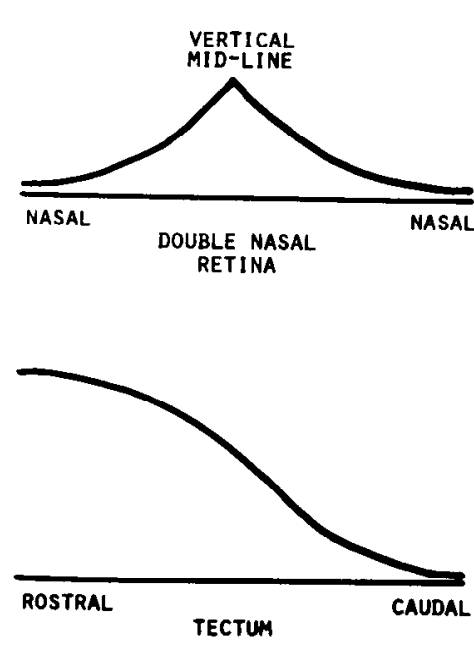

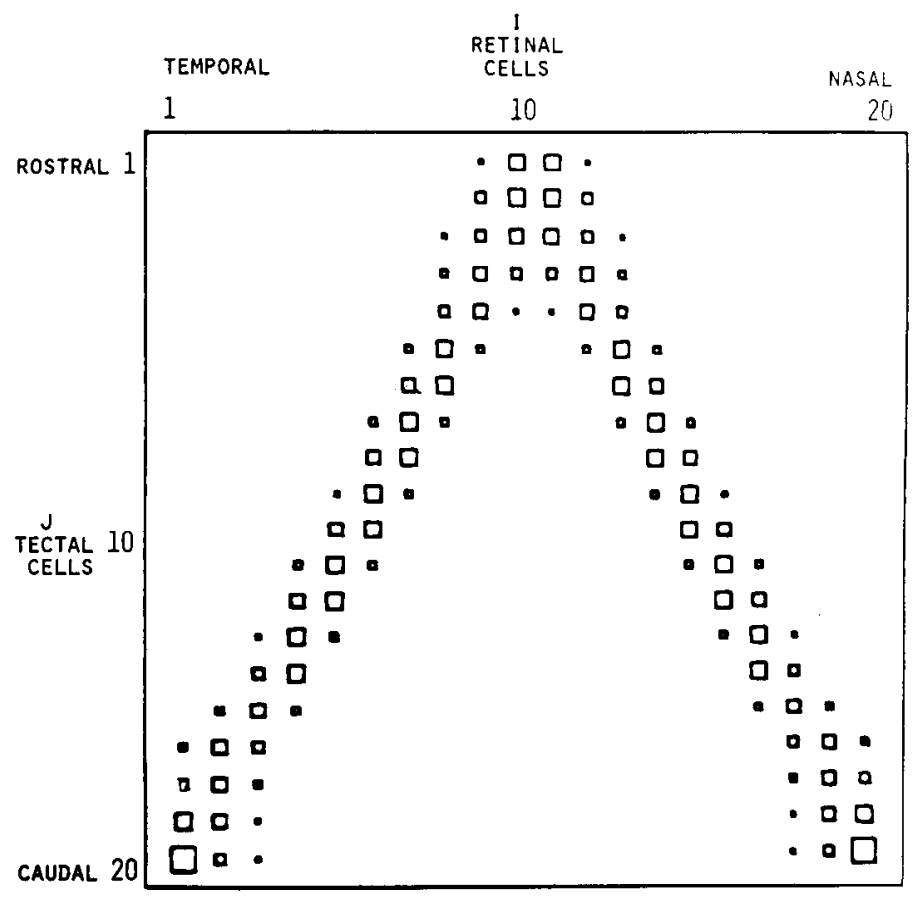

(B)

Figure 15. The double nasal compound eye was assumed in the model to have mirror-symmetric markers as in $A$. A double expanded map resulted $(B)$, assuming that the two half-retinae could activate tectal cells independently. 
Interspecies differences in plasticity. The present model accounts for experimental results from both goldfish and frogs. However, there are clear differences between these species in the plasticity that they exhibit during regeneration. Goldfish readily show expansion and compression, whereas frogs generally do not (see Edds et al., 1979). Retinotectal connections in frogs are evidently less modifiable than those in goldfish. The model suggests a basis for these interspecies differences in plasticity. In particular, if frog projections involve a greater range of adhesiveness $\left[c_{i j \max }^{\mathrm{frog}}-c_{i j \min }^{\mathrm{frog}}>c_{i j \max }^{\mathrm{fish}}-c_{i j \min }^{\mathrm{ish}}\right.$ or if the magnitudes of the adhesion coefficients are greater $\left[c_{i j}^{\text {frog }}\right.$

$\left.>c_{i j}^{\text {fish }}\right]$, this would account for the increased stability (hence the reduced modifiability) of the resultant connections. Also, it may be recalled that the mechanism for synaptic strength decay postulated receptor protein destabilization in the presence of asynchronous activity. If the rate of this destabilization ( $\alpha$ in equation 2 ) is considerably slower in frogs than in fish, this would account for the reduced plasticity of the former.

Concluding remarks. The present model incorporates the chemospecificity hypothesis in its postulation of fixed marker gradients in both retina and tectum. It has been shown that this fixed chemical specification is entirely compatible with the plasticity in retinotectal connections which has been described in a number of experimental contexts. There is no need to assume marker regulation. Furthermore, it has been shown that this specification can be very nominal, in terms of both its magnitude and spatial extent. Very shallow marker gradients suffice to organize the retinotectal map. If only a fraction of the cells are labeled such that a patch of ordered projection can form, this can serve as a nucleating center from which the rest of the map can organize.

Direct molecular evidence is needed to confirm or deny the basic assumption of marker-based chemospecificity. The present model suggests that the task of finding marker gradients may be very difficult in that they need not be large nor ubiquitous. The available experimental evidence is scant but suggestive. It is hoped that assays based on monoclonal antibodies will facilitate the search for the molecules involved in retinotectal mapping.

As to the hypothesis of synaptic plasticity, evidence for this is also sparse but could come from studies of the electrical/chemical events associated with retinotectal synaptogenesis. The influence of retinal ganglion cell activity, or more precisely, the timing of neural activity, as well as the possibility of neighbor correlations in retinal and tectal cell depolarization could be investigated further to confirm or refine the mechanisms of synaptic modification proposed in the present model.

\section{Mathematical Appendix}

Nomenclature and parameter values used. The nomenclature and parameter values used are: $\boldsymbol{a}_{i}, \boldsymbol{a}_{j}$, concentration of $a$ marker in the $i$ th retinal fiber or $j$ th tectal cell, respectively; the range of $a_{i}$ and $a_{j}$ is [1,2] (equations $3) ; b_{j^{\prime}, j}$, strength of intratectal connections: $b_{j^{\prime}, j}=0.25$ for $j^{\prime}=j-1, j+1$; otherwise, $b_{j^{\prime}, j}=0$ (equation 1 ); $c_{i j}$, chemospecific adhesion of the $i$ th retinal fiber and $j$ th tectal cell (equation 4$) ; n_{i}, n_{j}$, normalization constants for the synaptic strength matrix: $n_{i}=n_{j}=1$ (equations 5);
$N_{r}, N_{t}$, number of cells in the retinal and tectal arrays, respectively: $N_{r}=N_{t}=20$ or 40 (equation 3); $r_{i}$, electrical (activity) state of the $i$ th retinal fiber: $r_{i}=1$ if the cell is "on" otherwise, $r_{i}=0 ; s_{i j}$, synaptic strength between the $i$ th retinal fiber and $j$ th tectal cell (equation 2$) ; s_{i j \min }$, low level synaptic strength threshold below which $s_{i j}$ set $=0$ : $s_{i j \min }=0.009 ; t_{j}$, depolarized state of $j$ th tectal cell (equation 1); $\Delta t$, time increment of algorithm; the range of $\Delta t$ is $[0.05,0.5] ; \alpha$, rate constant for synaptic destabilization (equation 2): $\alpha=0.1 ; \xi$, coefficient of adhesiveness: $\xi=1$ (equation 4 ); $\Omega$, flux term (equation 2); the range of $\Omega$ is [0.00001, 0.001].

Inlerpretation of units. The units of the differential equation governing synaptic strength are as follows: $r_{i}$, which is the presence or absence of current flowing across the subsynaptic membrane, is in milliamperes; $t_{j}$ is the corresponding postsynaptic voltage in millivolts. Thus, $r_{i} t_{j}$ has the dimensions of power. Given that $s_{i j}$ is dimensionless, measuring relative synaptic strength $c_{i j}$ has the dimension of inverse energy measured in units of $\mathrm{ergs}^{-1}$, and $\alpha$ is in units of millivolts $\cdot$ seconds ${ }^{-1}$.

The algorithm. (1) $a_{i}$ and $a_{j}$ are assigned to each cell (equations 3 ) and adhesiveness $c_{i j}$ is calculated according to equation 4 . All the $s_{i j}$ values are set initially to $0,0.05$ or a random number in the range of $[0.01,0.1]$. (2) A randomly chosen cluster of retinal fibers then is activated by setting $r_{i-1}=r_{i}=r_{i}+1=1$. (3) Tectal cell depolarization is calculated from equation 1. (4) Changes of synaptic strength then are calculated according to equation 2 in the form: $s_{i j}(t+\Delta t)=s_{i j}(t)+\Delta t\left[c_{i j} r_{i} t_{j}-\right.$ $\alpha t_{j}$ ]. (5) The threshold of synaptic strength is checked: if $s_{i j}<s_{i j \min }$, the $s_{i j}$ is set $=0$. (6) The flux term is added: $s_{i j}=s_{i j}+\Omega$, where $\Omega$ is a random number in the range of $[0.0001,0.001]$. (7) Competition is introduced by normalizing the $s_{i j}$ matrix according to equations 5. (8) A new cluster of retinal cells then is activated and the algorithm is repeated. (9) Regeneration operations are simulated by changing $N_{r}, N$, or marker distributions where appropriate (i.e., translocations, rotations). The values of $N_{r}$ or $N$, used in equations 3 are not changed, however, as the assumption of marker regulation is not made. (10) Following "surgery," all $s_{i j}$ values are set back to initial conditions to simulate total optic nerve cut. Partial optic nerve cut is simulated by leaving the appropriate $s_{i j}$ values at their "pre-surgery" values. (11) The simulations were programmed in Basic or FORTRAN IV and run on a PDP-8 or IBM 360.

\section{References}

Attardi, D. G., and R. W. Sperry (1963) Preferential selection of central pathways by regenerating optic fibers. Exp. Neurol. 7: 46-64

Balsamo, J., J. McDonough, and J. Lilien (1976) Retinotectal connections in the embryonic chick: Evidence for regionally specific cell surface components, which mimic the pattern of innervation. Dev. Biol. 49: 338-346.

Barbera, A. J. (1975) Adhesive recognition between developing retinal cells and the optic tecta of the chick embryo. Dev. Biol. 46: 167-191.

Barbera, A. J., R. B. Marchase, and S. Roth (1973) Adhesive recognition and retinotectal specificity. Proc. Natl. Acad. Sci. U. S. A. 70: 2482-2486.

Bell, G. I. (1978) Models for the specific adhesion of cells to cells. Science 200: 618-627. 
Brindley, G. S. (1967) The classification of modifiable synapses and their use in models for conditioning. Proc. R. Soc. Lond. (Biol.) 168: 361.

Bunt, S. M., and T. J. Horder (1977) A proposal regarding the significance of simple mechanical events, such as the development of the choroid fissure, in the organization of central visual projections. J. Physiol. (Lond.) 272: 10-12.

Bunt, S. M., T. J. Horder, and K. A. C. Martin (1978) Evidence that optic fibers regenerating across the goldfish tectum may be assigned termination sites on a "first-come, first served" basis. J. Physiol. (Lond.) 276: 45-46.

Changeux, J. -P., and A. Danchin (1976) Selective stabilization of developing synapses as a mechanism for the specification of neuronal networks. Nature 264: 705-711.

Chung, S. H., and J. Cooke (1975) Polarity of structure and ordered nerve connections in the developing amphibian brain. Nature 258: 126-132.

Constantine-Paton, M., and P. Ferrari-Eastman (1979) Tectal connectivity in the frog following embryonic removal of eye primordia. Soc. Neurosci. Abstr. 5: 156.

Cook, J. E., and T. J. Horder (1977) The multiple factors determining retinotopic order in the growth of optic fibers into the optic tectum. Philos. Trans. R. Soc. Lond. (Biol.) 278: 261-276.

Devor, M., and G. E. Schneider (1975) Neuroanatomical plasticity: The principle of conservation of total axonal arborization Inst. Natl. Sante Rech. Med. Symp. 43: 191.

Edds, M. V., G. E. Schneider, R. M. Gaze, and L. N. Irwin (1979) Specificity \& plasticity of retinotectal connections. Neurosci. Res. Program Bull. 17: 2.

Edwards, M. A., and M. Jacobson (1979) Permeable and impermeable tectal barriers in goldfish: Different effects in rostral compression and caudal escape by optic fibers in goldfish. Soc. Neurosci. Abstr. 5: 625.

Fraser, S. E., and R. K. Hunt (1980) Retinotectal specificity: Models and experiments in search of a mapping function. Annu. Rev. Neurosci. 3: 319-352.

Gaze, R. M., and S. C. Sharma (1970) Axial differences in the reinnervation of the goldfish optic tectum by regenerating optic nerve fibers. Exp. Brain Res. 10: 171-181.

Gaze, R. M., M. Jacobson, and T. Szekely (1963) The retinotectal projection in Xenopus with compound eyes. J. Physiol. (Lond.) 165: 484-499.

Gaze, R. M., M. Jacobson, and G. Szekely (1965) On the formation of connections by compound eyes in Xenopus. J. Physiol. (Lond.) 176: 409-417.

Gaze, R. M., M. J. Keating, and S. H. Chung (1974) The evolution of the retinotectal map during development in Xenopus. Proc. R. Soc. Lond. (Biol.) 185: 301-330.

Gaze, R. M., J. D. Feldman, J. Cooke, and S. -H. Chung (1979) The orientation of the visuotectal map in Xenopus: Developmental aspects. J. Embryol. Exp. Morphol. 53: 39-66.

George, S. A., and W. B. Marks (1974) Optic nerve terminal arborizations in the frog: Shape and orientation inferred from electrophysiological measurements. Exp. Neurol. 42: 467-482.

Glaser, L., R. Santala, D. I. Gottlieb, and R. Merrell (1977) Cellcell recognition in embryonal nervous system. In Cell \& Tissue Interactions, J. W. Lash and M. M. Burger, eds., pp. 197-208, Raven Press, New York.

Hebb, D. O. (1949) Organization of Behavior, Wiley, New York.

Hope, R. A., B. J. Hammond, and R. M. Gaze (1976) The arrow model: Retinotectal specificity and map formation in the goldfish visual system. Proc. R. Soc. Lond. (Biol.) 194: 447466.

Horder, T. J. (1971) Retention, by fish optic nerve fibers regenerating to new terminal sites in the tectum of 'chemospecific' affinity for their original sites. J. Physiol. (Lond.) 216: 53P$55 \mathrm{P}$.
Horder, T. J., and K. A. C. Martin (1978a) Morphogenetics as an alternative to chemospecificity in the formation of nerve connections. In Cell-Cell Recognition, A. S. G. Curtis, ed., pp. 275-358, Cambridge University Press, New York.

Horder, T. J., and K. A. C. Martin (1978b) Morphogenetics as an alternative to chemospecificity in the formation of nerve connections. Symp. Soc. Exp. Biol. 32: 275-358.

Horton, J. C., M. M. Greenwood, and D. H. Hubel (1979) Nonretinotopic arrangement of fibres in cat optic nerve. Nature 282: 720 .

Hunt, R. K. (1976) Position dependent differentiation of neurons. In Developmental Biology: Pattern Formation: Gene Regulation; ICN.UCLA Symposium, D. MacMahon and C. F. Fox, eds., pp. 227-256, Benjamin, New York.

Hunt, R. K. (1977) Competitive retinotectal mapping in Xenopus. Biophys. J. 17: 128a.

Hunt, R. K., and M. Jacobson (1972a) Development and stability of positional information in Xenopus retinal ganglion cells. Proc. Natl. Acad. Sci. U. S. A. 69: 780-783.

Hunt, R. K., and M. Jacobson (1972b) Specification of positional information in retinal ganglion cells of Xenopus. Proc. Natl. Acad. Sci. U. S. A. 69: 2860-2864.

Hunt, R. K., and M. Jacobson (1974) Development of neuronal locus specificity in Xenopus retinal ganglion cells after surgical eye transection or after fusion of both eyes. Dev. Biol. 40: $1-15$.

Jacobson, M., and R. L. Levine (1975a) Plasticity in the adult frog brain: Filling the visual scotoma after excision or translocation of parts of the optic tectum. Brain Res. 88: 339-345.

Jacobson, M., and R. L. Levine (1975b) Stability of implanted duplicate tectal positional markers serving as targets for optic axons in adult frogs. Brain Res. 92: 468-471.

Lazar, G., and G. Szekely (1969) Golgi studies on the optic center of the frog. Brain Res. 16: 1.

Levine, R., and M. Jacobson (1974) Development of optic nerve fibers is determined by positional markers in the frog's tectum. Exp. Neurol. 43: 527-538.

Lilien, J., J. Hermolin, and P. Lipke (1978) Molecular interactions in specific cell recognition. In Specificity of Embryological Interactions, D. Garold, ed., pp. 131-156, Wiley, New York.

Marchase, R. B., A. J. Barbera, and S. Roth (1975) A molecular approach to retinotectal specificity. Ciba Found. Symp. 29: 315-327.

Martin, K. A. C. (1978) Combination of fiber-fiber competition and regional tectal differences accounting for the results of tectal graft experiments in goldfish. J. Physiol. (Lond.) 276: 44-45.

Mason, C. A., E. H. Polley, and R. W. Guillery (1979) Retinotopic organization of axons in the optic nerve and tract of normal and Siamese cats. Soc. Neurosci. Abstr. 5: 795.

Mastronarde, D. N. (1979) Coupling between Y cells of like center type in the cat retina. Invest. Ophthalmol. Vis. Sci. Suppl. 18: 78 .

Meyer, R. L. (1975) Tests for regulation in the goldfish retinotectal system. Anat. Rec. 181: 427.

Meyer, R. L. (1978) Deflection of selected optic fibers into a denervated tectum in goldfish. Brain Res. 155: 213-217.

Meyer, R. L. (1979) Retinotectal projection in goldfish to an inappropriate region with a reversal in polarity. Science 205 : 819.

Polyak, S. A. (1975) The Vertebrate Visual Pathway, University of Chicago Press, Chicago.

Prestige, M., and D. Willshaw (1975) On a role for competition in the formation of patterned neural connections. Proc R. Soc. Lond. (Biol.) 190: 77-98.

Rho, J. H. (1978) Cell interactions in retinotectal mapping. Biophys. J. 21: 137.

Rodieck, R. W. (1973) The Vertebrate Retina, W. H. Freeman, 
San Francisco.

Rusoff, A. C. (1980) Further rules for order in the goldfish optic nerve. Soc. Neurosci. Abstr. 6: 294.

Schmidt, J. T. (1978) Retinal fibers alter tectal positional markers during the expansion of the half retinal projection in goldfish. J. Comp. Neurol. 177: 279-300.

Schmidt, J. T., C. M. Cicerone, and S. S. Easter (1978) Expansion of the half-retinal projection to the tectum in goldfish: An electrophysiological and anatomical study. J. Comp. Neurol. 177: 257-278.

Scholes, J. H. (1979) Nerve fibre topography in the retinal projection to the tectum. Nature 278: 620 .

Sharma, S. C. (1969) Restoration of the visual projection from the retina to the rotated tectal implants in adult goldfish. Physiologist 12: 354 .

Sharma, S. C., and R. M. Gaze (1971) The retinotopic organization of visual responses from tectal reimplants in adult goldfish. Arch. Ital. Biol. 109: 357-366.

Sharma, S. C., and M. Romeskie (1977) Immediate 'compression' of the goldfish retinal projection to a tectum devoid of degenerating debris. Brain Res. 134: 1-4.

Sperry, R. W. (1941) The effect of crossing nerves to antagor-stic muscles in the hind limbs of the rat. J. Comp. Neurol. 75: $1-19$.

Sperry, R. W. (1944) Optic nerve regeneration with return of vision in anurans. J. Neurophysiol. 7: 57-69.

Sperry, R. W. (1949) Reimplantation of eyes in fishes with recovery of vision. Proc. Soc. Exp. Biol. Med. 71: 80-81.

Stent, G. S. (1973) A physiological mechanism for Hebb's postulate of learning. Proc. Natl. Acad. Sci. U. S. A. 70: 9971001.

Straznicky, K. (1978) The acquisition of tectal positional specification in Xenopus. Neurosci. Lett. 9: 177.

Straznicky, K., and R. M. Gaze (1971) The growth of the retina in Xenopus laevis: An autoradiographic study. J. Embryol. Exp. Morphol. 26: 67-79.

Straznicky, K., and R. M. Gaze (1972) The development of the tectum in Xenopus laevis: An autoradiographic study. J. Embryol. Exp. Morphol. 28: 87-115.
Szekely, G., G. Setalo, and G. Lazar (1973) Fine structure of the frog's optic tectum: Optic fibre termination. J. Hirnforsch. 14: 189 .

Uttley, A. M. (1956) Conditional probability machines and conditioned reflexes. In Automata Theory, C. E. Shannon and J. M. McCarthy, eds., pp. 273-275, Princeton University Press, Princeton, NJ.

von der Malsburg, C., and D. J. Willshaw (1977) How to label nerve cells so that they can interconnect in an orderly fashion. Proc. Natl. Acad. Sci. U. S. A. 74: 5176-5178.

Willshaw, D. J., and C. von der Malshurg (1976) How patterned neural connections can be set up by self-organization. Proc. R. Soc. Lond. (Biol.) 194: 431-445.

Willshaw, D. J., and C. von der Malsburg (1979) A marker induction mechanism for the establishment of ordered neural mappings: Its application to the retinotectal problem. Philos. Trans. R. Soc. Lond. (Biol.) 287: 203.

Wolpert, L. (1969) Positional information and the spatial pattern of cellular differentiation. J. Theor. Biol. 25: 1-47.

Yoon, M. G. (1971) Reorganization of retinotectal projection following surgical operations on the optic tectum in goldfish. Exp. Neurol. 33: 395-411.

Yoon, M. G. (1972a) Transposition of the visual projection from the nasal hemi-retina onto the foreign rostral zone of the optic tectum in goldfish. Exp. Neurol. 37: 451-462.

Yoon, M. G. (1972b) Reversibility of the reorganization of the retinotectal projection in goldfish. Exp. Neurol. 35: 565-577.

Yoon, M. G. (1973) Retention of the original topographic polarity by the $180^{\circ}$ rotated tectal reimplant in young adult goldfish. J. Physiol. (Lond.) 233: 575-588.

Yoon, M. G. (1975a) Topographic polarity of the optic tectum studied by reimplantation of the tectal tissue in adult goldfish. Cold Spring Harbor Symp. Quant. Biol. 40: 503-519.

Yoon, M. G. (1975b) Readjustment of retinotectal projection following reimplantation of a rotated or inverted tectal tissue in adult goldfish. J. Physiol. (Lond.) 252: 137-158.

Yoon, M. G. (1976) Progress of topographic regulation of the visual projection in the halved optic tectum of adult goldfish. J. Physiol. (Lond.) 257: 621-643. 